\title{
Seismic response of a small-scale masonry cross vault: Experimental investigation by performing quasi-static and shake table tests
}

\section{Nicoletta Bianchini ( $\nabla$ nicoletta.bianchini@gmail.com )}

University of Minho School of Engineering: Universidade do Minho Escola de Engenharia https://orcid.org/0000-0003-4706-1815

\section{Nuno Mendes}

University of Minho School of Engineering: Universidade do Minho Escola de Engenharia

\section{Chiara Calderini}

University of Genoa Polytechnic School: Universita degli Studi di Genova Scuola Politecnica

\section{Paulo XAVIER Candeias}

LNEC DE: Laboratorio Nacional de Engenharia Civil Departamento de Estruturas

\section{Michela Rossi}

University of Genoa Polytechnic School: Universita degli Studi di Genova Scuola Politecnica

\section{Paulo Lourenço}

University of Minho School of Engineering: Universidade do Minho Escola de Engenharia

\section{Original Article}

Keywords: Cross vault, displacement-based assessment, experimental tests, quasi-static tests, seismic response, shake table tests

Posted Date: February 3rd, 2021

DOI: https://doi.org/10.21203/rs.3.rs-188815/v1

License: @ (i) This work is licensed under a Creative Commons Attribution 4.0 International License. Read Full License 


\section{Abstract}

The seismic safety assessment of 3D complex structural elements of historic buildings, such as cross vaults, is a challenge and experimental tests can provide relevant data for this purpose. This paper presents the results of two experimental campaigns in a reduced scale 3D printed vault characterized by asymmetric boundary conditions. The specimen adopted the typical geometry of groin vault (without ribs) and was made of polymeric bricks placed in an orthogonal bond disposition. The seismic behaviour of the vault was studied through quasi-static and dynamic tests using the shake table. In particular, an incremental dynamic analysis up to the collapse of the vault was carried out. The results obtained experimentally were analysed in terms of damage, collapse mechanisms, displacements, in-plane distortion and response spectrum-based analysis.

\section{Introduction}

Masonry cross vaults represent one of the most important structural typologies within European cultural heritage buildings. Mostly developed during the Roman Empire and in the period between the High Middle Ages and Renaissance, cross vaults reached a level of beauty and construction technique that still amazes the modern observer. For centuries, the experience and the "instructions" followed by ancient masons had been jealously collected in the so-called rules of thumb, which have guaranteed their long-lasting history (Gaetani et al. 2016). However, being conceived to withstand only gravitational loads, masonry vaults are threatened by seismic events (Doglioni, Moretti, and Petrini 1994; Regione Toscana 2003; National Civil Protection Service 2013; Podestà et al. 2010).

In this regard, considering the limited research in the field, the present paper aims at investigating the seismic behaviour of masonry groin vaults subjected to shear failure. This particular type of cross vault is the geometrical result of the intersection at a right angle of two semi-circular barrel vaults, characterised by the lack of diagonal ribs. Groin vaults are used namely in the covering of churches' naves, palaces' rooms and porticos.

The present research work has three main aims. The first one is to evaluate the three-dimensional damage and collapse mechanism of masonry cross vaults subjected to in-plane shear forces caused by the seismic action. In-plane shear is a common type of failure that occurs during an earthquake as it was widely observed during post-earthquake surveys (Arcidiacono et al. 2016; Carfagnini et al. 2018; Borri, Corradi, and Vignoli 2002).

The second aim of this research work is to assess the in-plane shear capacity of cross vaults in terms of forces and displacement, using two different experimental approaches. The first approach is more common and corresponds to the monotonic quasi-static tests performed by Rossi et al. in 2015 at the University of Genoa. In the second approach, an extensive shake table tests campaign was performed in the National Laboratory for Civil Engineering, Lisbon, Portugal (LNEC) within the context of the project "Seismology and Earthquake Engineering Research Infrastructure Alliance for Europe" (SERA). The crucial point of this campaign is that the same mock-up, a reduced scale (1:5) groin vault made of 3D printed 
polymeric blocks, has been used in the two approaches. There are very few examples of static and shake table tests performed in the same mock-up, as done e.g. in Calderini et al. $(2015 ; 2015)$ for the analysis of a scaled arch-pier system reinforced with tie-rods. The main results of these tests showed that, in general, the force and displacement capacity of the tested model is lower than the ones predicted by theoretical analysis; this may be attributed to the deformability of the system in both the elastic and inelastic range and the presence of imperfections in the contacts between blocks. On the other hand, shake table tests proved the importance of considering displacement capacity for the seismic assessment of ancient masonry structures and, even more, in the design of strengthening techniques. From these considerations, it was possible to compare in terms of displacements the two approaches, using the response spectra for a Single-Degree-Of-Freedom (SDOF) to assess the performance of the structure based on linear kinematic analysis (Cattari, Resemini, and Lagomarsino 2008; Lagomarsino and Resemini 2009; D'Ayala 2005). Even if such study led to important conclusions, the results are only valid for a 2D structure. The research presented in this paper aims at extending the study to a three-dimensional behaviour. The comparison between static and shake table tests is fundamental because, in the most recent codes and guidelines, nonlinear static analysis is still the most used type of analysis to assess the behaviour of the masonry structures (static approach) (Modena 2020; Bianchini et al. 2019). Still, nonlinear dynamic analysis, despite the heavier computational effort, may lead to more realistic results.

Finally, the third aim of this research work is related to the influence of different types of ground motion on the performance of the mock-up. Two types of seismic inputs were considered, namely a recorded ground motion (Emilia earthquake, Italy, 2012) and an artificial accelerogram based on the code spectrum.

\subsection{Shear failure investigation}

Historically, cross vaults showed advantages which made them more desirable than other vaults. Advantages include the structural stability, the simplicity and the flexibility to provide natural light to the interior places, and the aesthetics. At the same time, a cross vault requires less quantity of material when compared to other kinds of vaults (e.g. about half of the material of a barrel vault or two-thirds less material than a pavilion vault) and it is likely the most suitable horizontal element that allows transferring gravitational loading to piers in monumental buildings (Huerta 2004; Cangi 2012).

Despite the favourable behaviour of cross vaults under vertical static loads, the in-plane horizontal shear distortion is a damage mechanism recurrently observed during post-earthquake surveys. This kind of mechanism is rather unexplored, even if it is particularly common in single-nave churches or three-nave churches (Fig. 1) characterised by a large difference in stiffness between the nave and the façade and/or transept, and in palaces with laterally constrained porches or loggias (Rossi et al. 2015; Milani et al. 2016; De Matteis, Cacace, and Rouhi 2019). In rather common three-nave churches, the lower stiffness of the central nave's colonnade, compared to the external walls, can lead to differential displacements along the longitudinal direction and, consequently, to the development of shear damage in the horizontal structural elements. This failure is mainly identified by diagonal cracks and the mock-up used in the experimental campaign was designed to reproduce this failure using appropriate geometrical details and boundary conditions. 


\subsection{Experimental campaigns on masonry cross vaults}

Despite the fact that the present topic interests a significant amount of real cases across the world, only a few researchers worked on masonry cross vaults. Bertolesi et al. (2019) provided an overview about the academic interest on this topic, highlighting that less than 40 scientific papers deal with masonry cross vaults in the period from 1960 to 2018. Moreover, in the last four years, they account for less than $1 \%$ of all the documents dealing with historic masonry structures, as found by the authors of this paper. In addition, very few researchers dealt with full experimental campaigns on shear behaviour. Table 1 summarises experimental studies developed using different materials and types of tests. Mock-ups built at reducedscale represent an optimum solution to study the structural behaviour of masonry cross vaults and, consequently, have been recurrently used.

Table 1. Experimental works carried out in masonry vaults, from the 1970 s until the most recent works. 


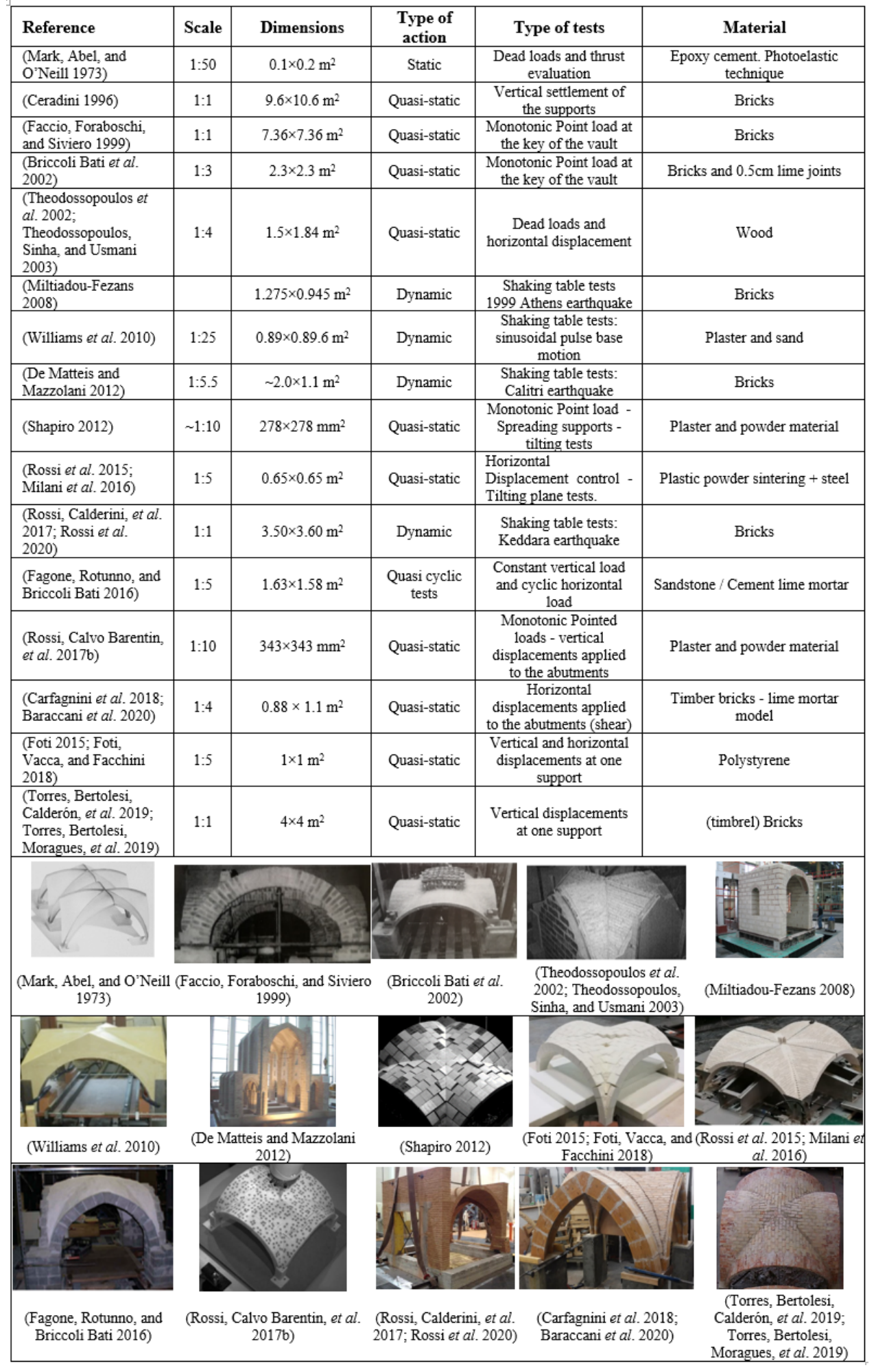

Mark and O'Neill (1973) presented the first experimental study on the subject, pointing out that the major in-plane vault forces are directed to its supports, validating ancient treatises and semi-empirical rules like the ones from Abraham (1934). Among other examples, Briccoli Bati et al. (2002) carried out a complete study in which different load conditions, symmetric and asymmetric boundary conditions, and strengthening techniques (mainly ties and Glass Fibre Reinforced Polymer externally bonded reinforcement) were evaluated. Theodossopoulos et al. $(2002 ; 2003)$ applied a horizontal displacement at the abutment, step by step, until reaching failure and highlighting the importance of the stability of the 
supporting piers and the abutments. This study has been crucial for the definition of the setup of this current research, since it stressed the fact that, under service loads, the cross vault showed a high reserve in strength, developing an asymmetric deformation pattern. Such behaviour is due to the difference between the stiffness of the wall and the nave arch. Williams et al. (2010) applied a unidirectional horizontal base shaking to a reduced scale model, representing the first shake table tests performed on a cross vault.

Foti et al. $(2015 ; 2018)$ introduced the important aspect of the masonry bond (or unit arrangement) at the shell of the vault. They studied parallel and orthogonal masonry bond from the experimental point of view, keeping the same geometry and material of the mock-up. Moreover, they applied displacement control tests, namely in the vertical, horizontal and diagonal directions. In the case of diagonal failure, the experimental laboratory model showed a premature collapse due to the presence of local hinges at some edge blocks' location.

The specimen tested by Rossi et al. $(2017 ; 2020)$ consists of the first shake table test performed on a 1:1 scale model. Even though the target failure mechanism was the one related to the shear failure, the vault collapsed at $0.4 \mathrm{~g}$, due to the activation of an out-of-plane mechanism that led to the development of the typical four-hinge mechanism.

Carfagnini (2018) and Baraccani (2020) performed also important works on this topic. They tested a 1:4 scaled specimen of a Gothic cross vault, subjected to shear deformation at two of its springings. It was shown that the initiation of cracks appeared perpendicularly to the diagonal ribs. It was also identified that the failure occurs at about $2.7 \%$ of the longitudinal span, which is in agreement with the few results on similar cases available in the scientific literature.

Still, the previous studies have different assumptions and limitations. Vaults are complex structural elements, characterised by three-dimensional behaviour and connected to different types of boundary conditions. Therefore, this research aims at contributing to overcome some limitations of the previous studies, reproducing a well-defined boundary condition setup and comparing the outputs obtained by a quasi-static investigation and by a shake table test, using the same reduced-scale model.

\section{Description Of The Mock-up And Test Setups 2.1 Geometry and materials}

The mock-up is composed of 3D printed plastic blocks with dry joints made at 1:5 scale. Figure 2 presents the geometry of the mock-up.

The shape and the geometry were defined by considering standard rules of thumb (Heyman 1995; Cangi 2009; Gaetani et al. 2015; Croci 2000; Huerta 2004) and a generic cross-section of a central bay located in a lateral nave of a three-nave church, derived from the intersection of two semi-circular barrel vaults. This example could be representative of a generic monumental church in Central Italy and other locations, 
generated by a squared base groin vault with a net span of $3.125 \mathrm{~m}$ span and $1.125 \mathrm{~m}$ rise at full scale (scaled 1:5).

In historical applications, it is common to find filling material placed above the shell of the vaults, which helps to reduce the thrust forces applied in the lateral piers. In this case, due to the setup, the application of filling material above the corners of the vault was not considered. The reason for this was the small size of the mock-up and, also the fact that, the filling material requires more complex boundary conditions, which could compromise the interpretation of the results.

The mock-up is composed of 1132 blocks (Figure 3), being 232 made fully of plastic and 880 made of plastic with a steel core (Figure 4). They have been 3D printed with the SLS (Selective Laser Sintering) technology, which allows to generate small-scale models by a numerically controlled machine starting from a 3D digital model, with high geometrical accuracy $( \pm 0.1 \mathrm{~mm})$ and a reasonably short time of production. Indeed, the time of production was estimated between 4-5 hours for the blocks of the shell, and 2 hours for the supports, counting a total duration of about 6-7 hours.

The adopted plastic material is a composite of zp150 powder and zb61 clear binder, printed with a ZPrinter 650. After production, the blocks have been impregnated with Z-bond 101 for improving the strength and durability. This technique was previously adopted by Rossi et al. (2017a) and ensures good stiffness and friction to take into account rigid block assumption, to allow the repeatability of the tests by minimizing the damage and to inhibit sliding between blocks. Indeed, the choice of adopting this particular material and technology was led by the need of performing several tests with different configurations without causing damage in the units.

The standard blocks (red blocks in Figure 3a) were designed considering the typical dimensions of clay bricks, namely $0.06 \times 0.12 \times 0.24 \mathrm{~m}^{3}$, in order to keep the classic bond stereotomy of medieval groin vaults. Blocks with different dimensions are placed along the outer edges of the webs to guarantee the offset of the joints. The blocks' shape is slightly trapezoidal to compensate for the absence of mortar between them. Special care was taken to design the stereotomy of the elements located along the diagonals (Figure $3 \mathrm{~b}$ ) to guarantee the correct interlocking between adjacent webs. Each block was identified by a numeric code, in order to easily rebuild the mock-up after each test.

Due to the accumulation of error in the 3D printing of the blocks, very thin steel plates have been properly designed and placed at the key of the vault to perfectly close its shell (Figure 2b). The selected arrangement of the blocks corresponds to the easiest one to be assembled (Rossi 2015) and it is called "orthogonal weaving". It allows to directly transfer the thrusts to the supports, being commonly found in medium and large vaults.

This masonry bond needs a temporary structure for the construction of the shells. Therefore, a scaffolding made of plywood has been designed, which is composed of four pieces corresponding to the vault webs. Once the mock-up is built, the scaffolding is removed by letting the pieces slide on proper inclined rails. Care and attention are required to remove the scaffolding, in order not to incur into undesirable 
configurations and defects. This aspect is important to ensure the repeatability of the tests, since defects in the construction process could compromise the analysis of the results and their comparisons.

The material density $(\rho)$ of the diagonals (Figure 2 ) was determined to be equal to $0.55 \pm 0.02 \mathrm{~g} / \mathrm{cm}^{3}$. It corresponds to a low-density value that could compromise the model stability under accidental actions. Therefore, as previously stated, the weight of the standard blocks was increased by inserting a steel core inside each block (Figure 4). In this way, the density of the standard blocks was set at the value of $2.70 \pm 0.05 \mathrm{~g} / \mathrm{cm}^{3}$. The final weight of the mock-up is about $35.6 \mathrm{~kg}$, while the whole structure is about 43 $\mathrm{kg}$, considering the steel base at the bottom of the mock-up. The friction angle $(\mu)$ of the blocks is equal to $29.6^{\circ} \pm 2.46^{\circ}$, which was determined by testing 12 samples of standard blocks. Table 2 summarises the properties of the materials of the reduced scale mock-up.

Table 2. Material properties of the mock-up.

\begin{tabular}{|llll|}
\hline Parameter & Standard blocks & Diagonals and abutments & Steel plates/corner \\
\hline Young's modulus [MPa] & 123.0 & 2.50 & 210000 \\
\hline Poisson's ratio [-] & 0.2 & 0.2 & 0.3 \\
\hline Density [g/ $\left./ \mathrm{cm}^{3}\right]$ & 2.7 & 0.55 & 7.8 \\
\hline
\end{tabular}

Although the mock-up presents different types of materials and the scale reduction factor equal to 5 is considerable, the mock-up is still able to represent the main features of masonry cross vaults. As stressed by ancient treatises (Heyman 1995), masonry cross vault's behaviour is mainly linked to the geometry of the system, namely size and shape, less depending on mechanical properties. The scale is less important for static tests (unless of important nonlinear geometric effects, such as in shallow arches or vaults) but it is much relevant for dynamic tests. Nevertheless, it is possible to scale up models numerically after validation in smaller scales.

The choice of using a dry joint mock-up is also an important aspect. In real structures, units are far from being rigid and with infinite strength but, in comparison, joints have rather low tensile strength and cohesion. In literature, several treatises refer that the elastic deformability of the joints does not significantly affect the response at the collapse, which is again correct for static loading. Still, neglecting the strength of the joints may slightly influence the static capacity, providing a conservative response. A dry joint mock-up allows to easily rebuild the mock-up after a test and to perform more tests. Therefore, it is very useful for research purposes and it can also represent ancient constructions that were built with dry joints or during times have experienced a significant loss of mortar due to the environmental conditions, becoming similar to dry joint structure (Lourenço and Ramos 2004; Pulatsu et al. 2019).

\subsection{Test setup}


The dynamic tests were performed in the National Laboratory of Civil Engineering, Lisbon, Portugal (LNEC), namely in the three axial shake table (Figure 5). The setup was carefully designed, aiming at obtaining the relevant outputs associated to the shear failure of the mock-up, with similar conditions to real prototypes and necessary for the performance assessment (Figure 5b).

In order to simulate the particular boundary conditions that cause an in-plane shear response of the vault, the special testing device adopted by Rossi et al. (2016) was used. It consists of a frame composed of four steel squared plates, linked to each other by the use of aluminium bar couples hinged at both ends with uniball joints. In this way, the distance between the abutments does not vary and their rotation along the vertical axis was prevented. Moreover, the abutments of the vault were rigidly fixed on the top of plates, which could freely move on a flat aluminium surface thanks to four spherical wheels.

As shown in Figure $5 c$, the abutments $p 1$ and $p 2$ were anchored to the ground with bolts, while $p 3$ and $p 4$ were let free to move on the flat surface. In Rossi, Calderini, and Lagomarsino (2016), the displacements were assigned along the $Y$ (longitudinal) direction (see Figure $5 \mathrm{~b}$ and $\mathrm{c}$ ), through an external actuator, for the quasi-static tests.

The instrumentation and boundary conditions used during the shake table tests were similar to those used for the quasi-static tests. At the same time, due to the small geometrical dimensions of the mock-up, specific instrumentation was also implemented. One linear variable displacement transducer $\left(\mathrm{LDVT}_{1}\right)$ was located at the N-W corner, measuring the relative longitudinal displacement of the movable piers. Six piezoelectric accelerometers ( $\mathrm{Acc}_{1 \mathrm{x}}, \mathrm{Acc}_{1 \mathrm{y}}, \mathrm{Acc}_{1 \mathrm{z}}, \mathrm{Acc}_{2 \mathrm{x}}, \mathrm{Acc}_{2 y}, \mathrm{Acc}_{2 z}$ in Figure $5 \mathrm{~b}$ ) were placed at the bottom of the vault to measure the response of the fixed plated, while five variable capacitance unidirectional accelerometers ( $\mathrm{Acc}_{3 \mathrm{y}}, \mathrm{Acc}_{4 \mathrm{x}}, \mathrm{Acc}_{5 z}, \mathrm{Acc}_{6 \mathrm{x}}, \mathrm{Acc}_{7 \mathrm{y}}$ ) were placed on the vault, since they are compatible with the dimension of the blocks in terms of dimensions and weight. Moreover, two optical cameras were used to record the response of the key of the western arch and the movable piers using automatic tracking, respectively, along the plane $x y\left(\mathrm{OP}_{1 x y}\right)$ and $y z\left(\mathrm{OP}_{2 y z}\right)$.

Two video cameras were used to record the tests: one exactly at the top of the mock-up, using scaffolding, and another located in front of the East façade on a tripod outside of the shake table. From those cameras, the collapse mechanism was evaluated (Section §4).

\section{Experimental Campaign Results}

In this Section, the main results obtained from both experimental campaigns with the reduced scale vault are presented. First, the monotonic quasi-static tests performed by Rossi et al. (2016) are briefly described. Next, the new dynamic identification tests and shake table tests performed at LNEC are presented.

\subsection{Monotonic quasi-static tests}

Rossi et al. (2016), simulated the simple shear mechanism of the masonry vault, as shown in Figure 6, in order to apply in-plane shear distortion. As previously described, on one side, two plates ( $p 1$ and $p 2)$ were 
fixed to the aluminium surface, while plates $p 3$ and $p 4$ were left free to move. The struts allow to maintain the same distance between the abutments and prevent also the rotation along the vertical axis. The displacement was applied by an external actuator at the $p 4$ plate.

The displacement $d s_{1}$ was monitored by means of a LVDT, while the related force $F s_{1}$ was measured by a load cell close to the displacement actuator. The development of the mechanisms up to the collapse was recorded by two high resolution/high frame rate cameras. It was observed that in general all webs show a typical four-hinge asymmetric arch mechanism, opposite in sign. The diagonal shear crack in the extrados can be noted and the first collapsing web is the one connecting $p 3$ and $p 4$ where the displacement is applied. The maximum force varies approximately from 13 to $17 \%$ of the total weight of the specimen $(422 \mathrm{kN})$ while the shear distortion (measured by the ratio of the displacement to the free span of the vault) is in the range $3.8-4.8 \%$ (Figure 6 ).

\subsection{Shake table tests}

\subsubsection{Dynamic identification tests}

Dynamic identification tests allow to estimate the modal properties of the mock-up. In this study, forced vibration tests were performed, in which the input and the response are measured. This kind of tests, characterized by a known input, can be defined as operational modal analysis. (Ramos 2007; Mendes, Lourenço, and Campos Costa 2014). A "white noise" random signal, with wide frequency range (0.1 - 40 $\mathrm{HZ}$ ) and low amplitude ( $3-8 \mathrm{~mm})$, was used, aiming at determining the modal parameters of the undamaged and damaged configurations. The amplitudes of the input were increased, aiming at evaluating the influence of the amplitude of the signal on the dynamic properties. This is particularly relevant given the use of dry joints, as their stiffness is highly dependent on the normal stress and the structural vault stiffness is also dependent on the crack opening of the joints. The amplitude of the signals is here defined in terms of nominal displacement. From Figure 7 it is possible to notice that the frequencies range from $3.22 \mathrm{~Hz}$ to $4.5 \mathrm{~Hz}$, with a variation of about $0.05 \mathrm{~Hz}$ per $1 \mathrm{~mm}$ of amplitude. Each symbol in Figure 7 represents a different construction of the mock-up. As expected, the increase of the signal amplitude (nominal displacement) causes a decrease in the frequency of the mock-up. The reduction of the frequencies is associated with the opening of the joints, i.e. to the damage on the mock-up, which is higher when the amplitude of the input is increased.

In order to verify the sensitivity of the model to the construction process, four different models for the mock-up were rebuilt using the same builders and the same techniques (Construction $A$ to $D$ ). The dynamic identification tests carried out in different days and after different rebuilds of the mock-up present similar frequencies for the same signal amplitude $(5 \mathrm{~mm})$, leading to the conclusion that the mock-up exhibits small scatter of the modal frequencies (between 3.9 and $4.2 \mathrm{~Hz}$ ), despite the different constructions or environmental conditions. This aspect further validates the methodology adopted for these tests. 
Moreover, the dynamic identification tests were used to monitor the dynamic properties of the mock-up, in particular the first natural mode of vibration, during the seismic tests. They have been repeated after each seismic test, aiming at identifying small variations in the frequency of the mock-up as an indicator of permanent damage due to movement of the blocks, sometimes not easily identified by the human eye (Sharma et al. 2020).

\subsubsection{Seismic tests}

In the seismic tests performed in the shake table, two types of ground motions were used, namely the Emilia earthquake and an artificial accelerogram. The first seismic input motion was recorded by the seismic station located in Mirandola (Italy) (Moretti, Azzara, and Bono 2013), which registered the Emilia Romagna's earthquake on the $29^{\text {th }}$ of May 2012. In this study, only the longitudinal component (northsouth direction) was considered. It corresponds to the y direction of the mock-up. The second seismic input is the artificial accelerogram compatible with the elastic response spectrum defined by the Italian Code (Ministero delle Infrastrutture e Trasporti 2018), considering the same municipality (Mirandola) and rock type of soil. Figure 8 presents the elastic response spectrum of the Italian Code NTC 2018 (for the horizontal component) and the spectrum of the artificial accelerogram. The spectrum of the Emilia target input is also plotted in same figure. The vertical dashed line represents the first natural frequency of the mock-up equal to $4.0 \mathrm{~Hz}$, corresponding to $0.25 \mathrm{~s}$, in which the spectral acceleration of the Emilia target input $(0.6 \mathrm{~g})$ is about $0.17 \mathrm{~g}$ above the spectral acceleration of the Italian Code $(0.43 \mathrm{~g})$.

In the same way, Figure 9 shows the time histories of the selected inputs, which correspond to $100 \%$ of the respective seismic action. The Emilia target input is characterised by a duration of $8.93 \mathrm{~s}$. Its peak ground acceleration (PGA) is equal to $284.6 \mathrm{mg}$ and the maximum displacement (PGD) is equal to $31.00 \mathrm{~mm}$, while its root mean square acceleration (RMSA) and root mean square displacement (RMSD) are respectively equal to $72.50 \mathrm{mg}$ and $7.09 \mathrm{~mm}$. The artificial accelerogram presents the same duration, a PGA equal to $173.3 \mathrm{mg}$, a maximum displacement equal to $16.00 \mathrm{~mm}$, its RMSA has a value of $46.75 \mathrm{mg}$ and the RMSD is equal to $7.87 \mathrm{~mm}$. The two inputs were also subjected to a signal processing using a high pass Butterworth filter with 8 poles and a cut-off frequency equal to $1 \mathrm{~Hz}$. Again, the seismic inputs were applied to the structure only longitudinally, i.e. along the north-south direction, in order to excite the movable piers and induce the shear failure in the vault.

The testing sequence of the vault is presented in Table 3 , in which the seismic action was applied with increasing amplitude until collapse and the model was rebuilt 3 times (indicated here as Construction 1 to 3). Before the first and after each seismic test, dynamic identification tests (DIT) were performed, with the amplitude of $5 \mathrm{~mm}$, in order to evaluate the decrease of frequencies as a function of the cumulative damage, which was almost equal to zero until $50 \%$ of the Emilia ground motion and until $100 \%$ of the artificial ground motion (Table 3 ). When only a few blocks fell during the test, the mock-up was repaired, in order to keep the same starting point to the mock-up (undamaged mock-up). In the case of Construction 3 , the mock-up was not repaired, aiming at simulating a sequence of shocks and the consequent accumulation of damage. 
Table 3. List of shaking table tests carried out on the reduced scale vault (chronological order).

\begin{tabular}{|c|c|c|c|c|c|c|c|}
\hline \multirow{2}{*}{\multicolumn{2}{|c|}{$\begin{array}{l}\text { Emilia input } \\
\text { DIT }\end{array}$}} & & & \multicolumn{4}{|c|}{ Artificial input } \\
\hline & & \multicolumn{2}{|c|}{ Input } & \multicolumn{2}{|l|}{ DIT } & \multicolumn{2}{|c|}{ Input } \\
\hline $\begin{array}{l}\text { Amplitude } \\
\text { [mm] }\end{array}$ & $\begin{array}{l}\text { Frequency } \\
{[\mathrm{Hz}]}\end{array}$ & $\%$ & Notes & $\begin{array}{l}\text { Amplitude } \\
\text { [mm] }\end{array}$ & $\begin{array}{l}\text { Frequency } \\
\text { [Hz] }\end{array}$ & $\%$ & Notes \\
\hline \multicolumn{8}{|c|}{ Construction 1} \\
\hline \multirow[t]{2}{*}{5} & 4.10 & & & & & 50 & \\
\hline & & 10 & & 5 & 4.00 & & \\
\hline \multirow[t]{2}{*}{5} & 4.10 & & & & & 75 & \\
\hline & & 25 & & 5 & 4.00 & & \\
\hline \multirow[t]{2}{*}{5} & 4.00 & & & & & 100 & \\
\hline & & 50 & Recovered & 5 & 3.90 & & \\
\hline \multirow[t]{2}{*}{5} & 3.91 & & & & & 125 & \\
\hline & & 75 & Collapse & 5 & 3.71 & & \\
\hline \multicolumn{2}{|c|}{ Construction 2} & & & & & 150 & \\
\hline \multirow[t]{2}{*}{5} & 3.61 & \multicolumn{2}{|c|}{$\begin{array}{l}\text { *Initial minor } \\
\text { damage }\end{array}$} & 5 & 3.35 & & \\
\hline & & 60 & Collapse & & & 200 & Collapse \\
\hline \multicolumn{8}{|c|}{ Construction 3} \\
\hline \multirow[t]{2}{*}{5} & 4.00 & & & & & & \\
\hline & & 55 & Unrecovered & & & & \\
\hline \multirow[t]{2}{*}{5} & 3.42 & & & & & & \\
\hline & & 25 & Aftershock1 & & & & \\
\hline \multirow[t]{2}{*}{5} & 3.22 & & & & & & \\
\hline & & 35 & Aftershock 2 & & & & \\
\hline
\end{tabular}

The input applied in the seismic tests were scaled in order to follow the Cauchy and Froude's similitude. According to this similitude law (Carvalho 1998), the time variable is scaled according to the relation $0^{0.5}=5^{0.5}$, in which $/$ is the geometric scale factor.

\section{Analysis Of The Results}


The damage, collapse mechanisms and the main quantitative outputs of the response of both mock-ups were evaluated and are next presented.

To compare the results of the static tests carried out by Rossi et al. (2016) with the shake table tests (ST), the analysis of collapse mechanism was adopted, in which a sequence of photos, with the number and locations of the hinges, was used. Looking at Figure 10, the centre of the vault is the first to collapse in both tests, due to its geometrical configuration and the verticality of the joints. The fall of the blocks at the centre of the vault does not interfere with the shear failure, which is the first to occur. During the shake table tests, the hinges started to appear from the East side of the mock-up between $p 1$ and $p 2$, the fixed piers, while during the quasi-static tests the first hinge occurred between the movable piers (west side) $p 3$ and $p 4$. Analysing the dynamic test results, the external edges (North and East side) continue to stand, even when the other sides already fell down. The hinges are located at the East façade, both for the Emilia and the artificial inputs (Figure 10).

The steel plates at the corners make the boundaries of the shell of the vault stiffer and, therefore, two hinges occur where the steel plates do not act anymore. This is in agreement with the prediction of Oppenheim and De Lorenzis et al. (Oppenheim 1992; De Lorenzis, Dejong, and Ochsendorf 2007), based on the minimum energy formulations. Considering the response obtained from the shake table tests, the arch mechanism is clear (four hinges) and it is mainly associated to the edge side where the supports are fixed and the structure is more rigid (Figure 10).

Different loading distribution leads to a different response. This aspect was widely observed for the behaviour of similar structures like arches. In the case of the vault, the three-dimensional complexity of the structure amplifies this concept. Indeed, the quasi-static tests are mainly associated with the gravitational set of loads, while the shake table tests consider the inertial force acting on the structure.

The main objective is to assess the cross-vault behaviour independently from the load type and then to stress the fact that for this kind of structures, the nonlinear static approach represents an approximation of the reality that does not replicate all loading scenarios. At the same time, even two different inputs in the shaking table lead to different quantitative conclusions due to the spectra contents of the seismic action itself. Regarding the comparison between the two ground motions used during the shake table tests, and as shown in Table 4, the specimen remained undamaged until the scaling factor of $75 \%$ and $200 \%$ for the Emilia and artificial inputs, respectively.

Table 4. Incremental dynamic testing sequence with the respective peak ground acceleration (PGA), peak ground velocity (PGV) and peak ground displacement (PGD). 


\begin{tabular}{|c|c|c|c|c|c|c|c|c|c|}
\hline \multicolumn{5}{|c|}{ Emilia input } & \multicolumn{5}{|c|}{ Artificial input } \\
\hline $\begin{array}{l}\text { Test } \\
\text { input }\end{array}$ & PGA & PGV & PGD & $\begin{array}{l}\text { Damage } \\
\text { notes }\end{array}$ & $\begin{array}{l}\text { Test } \\
\text { input }\end{array}$ & PGA & PGV & PGD & $\begin{array}{l}\text { Damage } \\
\text { notes }\end{array}$ \\
\hline$\%$ & [mg] & {$[\mathrm{mm} / \mathrm{s}]$} & {$[\mathrm{mm}]$} & & $\%$ & [mg] & {$[\mathrm{mm} / \mathrm{s}]$} & [mm] & \\
\hline 10 & 3.55 & 7.23 & 0.31 & & 10 & 1.23 & 0.53 & 0.16 & \\
\hline 25 & 19.17 & 17.22 & 1.96 & & 25 & 8.72 & 3.75 & 0.99 & \\
\hline 35 & 33.70 & 32.67 & 3.87 & & 50 & 39.30 & 14.52 & 3.99 & \\
\hline 50 & 70.65 & 64.58 & 7.94 & $\begin{array}{l}\text { Fall of the } \\
\text { key blocks }\end{array}$ & 75 & 94.27 & 32.47 & 8.99 & \\
\hline 55 & 84.85 & 77.80 & 9.53 & $\begin{array}{l}\text { Opening of } \\
\text { the diagonal } \\
\text { crack (NW - } \\
\text { SE) }\end{array}$ & 100 & 172.30 & 58.15 & 16.10 & \\
\hline 60 & & & & $\begin{array}{l}\text { Collapse } \\
\text { (problems in } \\
\text { the setup) }\end{array}$ & 125 & 344.19 & 95.80 & 25.07 & $\begin{array}{l}\text { Fall of } \\
\text { the key } \\
\text { blocks }\end{array}$ \\
\hline \multirow[t]{2}{*}{75} & 160.10 & 139.47 & 17.67 & Collapse & 150 & 435.12 & 135.72 & 36.27 & $\begin{array}{l}\text { Opening } \\
\text { of the } \\
\text { diagonal } \\
\text { crack } \\
\text { (NW - } \\
\text { SE) }\end{array}$ \\
\hline & & & & & 200 & 763.7 & 241.21 & 64.70 & Collapse \\
\hline
\end{tabular}

It is possible to notice that the impulsive nature of the Emilia earthquake, caused a rapid collapse of the vault, in comparison with the artificial accelerogram (Table 4). However, the type of collapse mechanism remains the same, in terms of the evolution of damage and formation of the hinges (Figure 11). Both types of seismic action show a clear shear behaviour, which occurs along the diagonals that join $p_{2}-p_{4}$ and $p_{1}$ $p_{3}$, due to the positive and negative direction of the accelerations at the base. It is notable also that the hinges interfere only with the parallel edges (East before and West later), while the transversal facades are not involved in the collapse and they keep a simple-arch behaviour until the end of the tests. These observations are valid for every amplitude of the shake table tests, starting from the value of amplitudes that could cause a more relevant state of damage. For the sake of clarity and conciseness, only the collapse mechanism before reaching the collapse itself is compared, namely for the $75 \%$ of the Emilia input and the $200 \%$ of the artificial input.

The performance of the mock-up in terms of displacements and accelerations require a more detailed analysis. It is confirmed that the impulsive nature of the Emilia earthquake significantly influences the response of the structure and, even with lower values of spectral acceleration, induces earlier damage in 
the structure. Acceleration and displacement response spectra of the several time histories are very different in content and peaks (Figure 12).

Table 5 shows some relevant outputs associated with the recorded response of the structure. Besides the fact that the content of the two inputs is different, the displacements recorded by the movable piers showed good consistency for all shake table tests. The values of drifts (ratio between the relative displacement and the span), recorded by the optical camera and the LVDT, placed respectively above the movable piers $p 3$ and $p 4$, ranges from $5.12 \%$ to $7.17 \%$, for both inputs. The average value is about $6 \%$, either for the Emilia input or the artificial input. It is noted that the difference between the two values obtained for the different types of inputs is less than $1 \%$ for the optical camera and about $0.1 \%$ for the LDVT. From the drifts, it is possible to conclude that under seismic motion the limit drift value that can cause the collapse is equal to $6 \%$. The ultimate drift value measured in the quasi-static tests was about $4.3 \%$ of its lateral edge. It has been shown in the past, e.g. for masonry building, that dynamic drifts are larger than quasi-static.

Table 5. Tests results for each dynamic input and the quasi-static tests.

\begin{tabular}{|c|c|c|c|c|c|c|c|c|c|}
\hline \multicolumn{5}{|c|}{ Emilia input } & \multicolumn{5}{|c|}{ Artificial input } \\
\hline \multirow{2}{*}{$\begin{array}{l}\text { Test } \\
\text { input }\end{array}$} & \multirow[t]{2}{*}{ PGA } & \multirow[t]{2}{*}{ PGV } & \multirow[t]{2}{*}{ PGD } & Damage & \multirow{2}{*}{$\begin{array}{l}\text { Test } \\
\text { input }\end{array}$} & \multirow[t]{2}{*}{ PGA } & \multirow[t]{2}{*}{ PGV } & \multirow[t]{2}{*}{ PGD } & Damage \\
\hline & & & & Notes & & & & & Notes \\
\hline$\%$ & {$\left[\mathrm{~m} / \mathrm{s}^{2}\right]$} & {$[\mathrm{mm} / \mathrm{s}]$} & {$[\mathrm{mm}]$} & & $\%$ & {$[\mathrm{~m} / \mathrm{s} 2]$} & {$[\mathrm{mm} / \mathrm{s}]$} & {$[\mathrm{mm}]$} & \\
\hline \multirow[t]{2}{*}{75} & 1.57 & 139.47 & 17.67 & Collapse & 200 & 7.49 & 241.21 & 64.70 & Collapse \\
\hline & & & & Instrument & \multicolumn{2}{|c|}{ Emilia input } & \multicolumn{2}{|c|}{$\begin{array}{l}\text { Artificial } \\
\text { input }\end{array}$} & $\begin{array}{l}\% \\
\text { Difference }\end{array}$ \\
\hline \multicolumn{4}{|c|}{ Maximum displacement $p 3[\mathrm{~mm}]$} & \multirow{2}{*}{$\begin{array}{l}\text { Optical } \\
\text { camera }\end{array}$} & \multicolumn{2}{|l|}{44.8} & \multicolumn{2}{|c|}{39.1} & \\
\hline \multicolumn{4}{|c|}{ Drift (displacement over span) [\%] } & & \multicolumn{2}{|l|}{7.17} & \multicolumn{2}{|c|}{6.26} & $0.91 \%$ \\
\hline \multicolumn{4}{|c|}{ Maximum displacement $p 4[\mathrm{~mm}]$} & \multirow[t]{2}{*}{ LVDT } & \multicolumn{2}{|l|}{32.0} & \multicolumn{2}{|c|}{32.6} & \\
\hline \multicolumn{4}{|c|}{ Drift (displacement over span) [\%] } & & \multicolumn{2}{|l|}{5.12} & \multicolumn{2}{|c|}{5.22} & $0.1 \%$ \\
\hline \multicolumn{4}{|c|}{ Drift average [\%] } & & \multicolumn{2}{|l|}{6.15} & \multicolumn{2}{|c|}{5.74} & \\
\hline \multicolumn{10}{|c|}{ Quasi-static tests (Rossi, Calderini, and Lagomarsino 2016) } \\
\hline \multicolumn{4}{|c|}{ Maximum displacement $p 4[\mathrm{~mm}]$} & LVDT & \multicolumn{4}{|c|}{$24.7-31.2$} & \\
\hline \multicolumn{4}{|c|}{ Drift (displacement over span) [\%] } & & \multicolumn{4}{|c|}{$3.8-4.8$} & \\
\hline
\end{tabular}

For an additional comparison between the types of input, the hysteretic behaviour of the reduced-scale vault is presented in Figure 13, in terms of a relation between the shear forces/horizontal inertial forces and the displacements. The shear forces developed in the structures, as well as the displacement, have been analysed based on the recorded acceleration and displacement time-histories. The base shear coefficient 
was calculated by dividing the inertial force associated with each web of the vault by its self-weight. Inertial forces associated with the webs of the vault were calculated by assuming the mass of the reference web to be lumped at the recording accelerometers. In fact, due to the geometrical symmetry of the mock-up, the mass associated with each web corresponds to $1 / 4$ of the total mass of the mock-up. The inertia forces were computed for each shake table test but, for sake of simplicity, only the most representative scenarios are presented in Figure 13. The shear coefficient was plotted versus the longitudinal displacement placed at the top of the west arch, measured by the optical camera $\mathrm{OP}_{2}$. Figure 13a, which refers to stages with the lower amplitudes, represents a linear elastic phase with a very low value of excitation. This behaviour is associated with the undamaged configuration of the vault, namely when the openings of the joint do not lead to the fall of blocks. The linear range is evident even for the hysteretic curves plotted at the amplitude of the collapse (Figure 13b), in which two vertical lines are associated with the initial phase. Then, very high nonlinear behaviour, for both inputs, is observed. As noticed before in the evaluation of the drifts, the hysteretic curves show also similarities when considering the Emilia input and the artificial input. The scattered behaviour of the curve is marked by the different slopes of the curves, which represents a change in terms of stiffness and permanent deformation. Emilia input and artificial input show a quite similar nonlinear behaviour, but mirrored in sign. In general, when the artificial input is applied, the structure is characterized by a higher capacity in terms of shear coefficient, while with the Emilia input the structure shows a higher deformation.

Despite the different response in terms of displacements, when compared with the quasi-static tests, it was observed that the maximum strength capacity ranged between $13-17 \%$ of the force/weight ratio, which is compatible with the value obtained by the shake table tests (Figure 13b). Figure 14 shows the plots for the incremental dynamic tests performed in the shake table tests, for the Emilia input and the artificial input. The maximum base shear at each stage of testing and the corresponding value of displacement recorded by the sensor located at the key of the west arch (OP2y), occurring at the same instant of time, is reported. The first points show the linear range of response, despite the difficulty to observe the differences in terms of stiffness due to the low level of amplitude. During this kind of tests, it is normal to get a better response for a medium value of amplitude and intensity. The tests with the Emilia input and the artificial input show a similar capacity in terms of base shear and deformations. This outcome is in line with what was obtained in previous research on reduced-scale mock-ups (Tomaževič 1999).

The differences in terms of inputs and response can be also identified in Figure 15. As Candeias et al. (2016) stressed, a straight line with a 1:1 slope means that the absolute accelerations are equal in the base and the other selected points of the mock-up. This means a rigid body motion, whereas if the slope is higher means that there is dynamic amplification in the mock-up. Finally, if there is an exponential increase of the plots with the increase of the input motion intensity, it means that the mock-up has reached the nonlinear behaviour. Looking at Figure $15 \mathrm{a}$ ), c), it is possible to observe the dynamic behaviour of the vault for the Emilia input. It can be defined as linear from the tests with $10 \%$ to $60 \%$, except for the point for the $55 \%$, which corresponds to the third construction (Table 3). This could be associated with some relative movements during the recording state of the sensor or due to the construction process. Before the collapse, firstly achieved with $75 \%$ of the seismic motion, it is possible to notice an exponential increase significantly 
evident from the accelerations recorded on the top of the movable piers $\left(A c_{3 y}, A c c_{7 y}\right)$, less remarkable for the ones placed on the fixed piers $\left(\mathrm{Acc}_{1 \mathrm{y}}, \mathrm{Acc}_{2 \mathrm{y}}\right)$.

On the other hand, for what concerns the artificial input, Figure 15b), d), the linear range was identified between the $10 \%$ and the $120 \%$ of the ground motion, while the exponential rate is mainly localised on the last two sequences of tests (150\% and $200 \%)$, when effectively the severe damage occurred.

\section{Conclusions}

This work describes a comprehensive experimental investigation composed by shake table tests developed for the characterisation of the shear failure of a reduced scale mock-up (1:5) of a 3D printed cross vault. Two experimental campaigns using different approaches of loading were discussed, namely: (a) monotonic quasi-static tests, previously performed by (Rossi, Calderini, and Lagomarsino 2016); (b) shake table tests applying the Emilia earthquake (2012) and an artificial accelerogram for the same zone. The shake table tests include also dynamic identification tests.

The objectives of this work were to evaluate the variation of the response considering the two different types of loading (quasi-static and dynamic) and the two different types of seismic action applied in the shake table tests (recorded vs. artificial accelerograms). The results were mainly compared in terms of maximum load capacity, drift/displacement capacity and collapse mechanisms.

The results obtained from the dynamic identification tests, performed before and after each seismic shake table test, allowed to evaluate the reduction of dynamic properties of the mock-up, which can be used as an indicator of the damage. The development of a three-hinge symmetric mechanism was observed in two webs during the quasi-static tests. When hinges became collinear the collapse occurred. On the other hand, a similar mirrored mechanism was obtained for the shake table tests, but the first location of the hinges appears between the fixed piers of the vault, associated with the stiffer behaviour of the fixed edge.

The displacement/drift levels achieved in the shake table tests were higher (about $6 \%$ of the span) than the ultimate displacement/drift obtained from quasi-static tests (about $4 \%$ of the span), using the same reduced scale vault. The capacity in terms of base shear was similar in both tests. The differences in terms of collapse between the Emilia earthquake and the artificial seismic input stresses the fact that, according to the most recent codes, a significant number of records must be selected in order to allow a better description of the safety of the structure (Lagomarsino and Cattari 2015).

Finally, this study, complemented by the dynamic identification tests, provides useful data for the development and calibration of reference numerical models, adopting different strategies, which then allow to evaluate the seismic behaviour of vaults with different geometry and seismic action.

\section{Declarations}

\section{Conflict of interests}


The authors certify that they have no affiliations with or involvement in any organization or entity with any financial interest, or non-financial interest in the subject matter or materials discussed in this manuscript.

\section{Acknowledgements}

The authors are grateful to the National Laboratory of Civil Engineering and all the technicians for providing the experimental data for the shake table tests. This work was partly financed by FCT Foundation for Science and Technology within the scope of the SERA.TA project "Seismic Response of Masonry Cross Vaults: Shaking table tests and numerical validations" and the PhD grant SFRH/BD/136831/2018.

\section{References}

Abraham D (1934) Viollet-Le-Duc et Le Rationalisme Médiéval. Bulletin Monumental. Vol. 93. Paris: Vicent, Fréal et Cie. https://doi.org/10.3406/bulmo.1934.10100.

Arcidiacono V, Cimellaro G. P, Piermarini E, Ochsendorf John A (2016) The Dynamic Behavior of the Basilica of San Francesco in Assisi Using Simplified Analytical Models. International Journal of Architectural Heritage 10 (7): 938-53. https://doi.org/10.1080/15583058.2016.1158333.

Baraccani S, Zauli L, Theodossopoulos D, Silvestri S (2020) Experimental Test on a Fibre-Reinforced Scaled Cross Vault Subjected to in-Plane Shear Displacements at the Springings. Construction and Building Materials 265: 120305.

Bertolesi E, Adam J M, Rinaudo P, Calderón P A (2019) Research and Practice on Masonry Cross Vaults - A Review. Engineering Structures:67-88.

Bianchini N et al. (2019) Seismic Assessment of Masonry Cross Vaults through Numerical Nonlinear Static and Dynamic Analysis. Paper presented at the 7th International symposium Conference on Computational Methods in Structural Dynamics and Earthquake Engineering, Crete, Greece, 24-26 June 2019.

Borri A et al. (2002) New Materials for Strengthening and Seismic Upgrading Interventions. Paper presented at the International Workshop in Ariadne.

Briccoli Bati S et al. (2002) Costruzioni Voltate in Muratura Prototipo Volta a Crociera.

Calderini, C et al. (2015) Shaking Table Tests of an Arch-Pillars System and Design of Strengthening by the Use of Tie-Rods. Bulletin of Earthquake Engineering 13 (1): 279-97 https://doi.org/10.1007/s10518-0149678-x.

Calderini C, Lagomarsino S (2015) Seismic Response of Masonry Arches Reinforced by Tie-Rods: Static Tests on a Scale Model. Journal of Structural Engineering 141 (5): 4014131-37. https://doi.org/10.1061/(ASCE)ST.1943-541X.0001079. 
Candeias P et al (2016) Experimental Assessment of the Out-of-Plane Performance of Masonry Buildings Through Shaking Table Tests Experimental Assessment of the Out-of-Plane Performance of Masonry Buildings. International Journal of Architectural Heritage 00 (00): 1-28.

https://doi.org/10.1080/15583058.2016.1238975.

Cangi G (2009) Ruolo Delle Volte e Tecniche Di Consolidamento. Vol. 2 (in Italian).

Cangi G (2012) Manuale Del Recupero Strutturale e Antisismico. DEl, Rome (in Italian).

Carfagnini C, Baraccani S, Silvestri S, Theodossopoulos D (2018) The Effects of In-Plane Shear Displacements at the Springings of Gothic Cross Vaults. Construction and Building Materials 186: 219-32. https://doi.org/10.1016/j.conbuildmat.2018.07.055.

Carvalho E (1998) Seismic Testing Structures. Paper presented at the $11^{\text {th }}$ European Conference on Earthquake Engineering, Rotterdam.

Cattari S, Resemini S, Lagomarsino S (2008) Modelling of Vaults as Equivalent Diaphragms in 3D Seismic Analysis of Masonry Buildings. Paper presented at the Structural Analysis of Historical Constructions Conference, London.

Ceradini V (1996) Modelli Sperimentali Di Volte in Tufo e Mattoni. In: La Meccanica Delle Murature Tra Teoria e Progetto, Messina, p 57-66 (in Italian)

Croci G (2000) General Methodology for the Structural Restoration of Historic Buildings: The Cases of the Tower of Pisa and the Basilica of Assisi. Journal of Cultural Heritage 1 (1): 7-18.

https://doi.org/10.1016/S1296-2074(99)00119-3.

D’Ayala D F (2005) Force and Displacement Based Vulnerability Assessment for Traditional Buildings. Bulletin of Earthquake Engineering 3 (3): 235-65. https://doi.org/10.1007/s10518-005-1239-x.

Doglioni, F, Moretti A, Petrini V (1994) Le Chiese e II Terremoto. Dalla Vulnerabilità Constatata Nel Terremoto Del Friuli Al Miglioramento Antisismico Nel Restauro. Verso Una Politica Di Prevenzione. Trieste: Lint Editoriale Associati. (in Italian).

Faccio P, Foraboschi P, Siviero E (1999) Volte in Muratura Con Rinforzi in FRP. L'Edilizia 7/8: 44-50. (in Italian).

Fagone M, Rotunno T, Briccoli Bati S (2016) The Groin Vaults of St. John Hospital in Jerusalem: An Experimental Analysis on a Scale Model. International Journal of Architectural Heritage 10 (May): 903-18. https://doi.org/10.1080/15583058.2016.1158331.

Foti D (2015) Structural Behaviour of Historical Stone Arches and Vaults: Experimental Tests and Numerical Analyses. Key Engineering Materials 2: 43-48. doi.org/10.4028/www.scientific.net/KEM.628.431-2. 
Foti D, Vacca V, Facchini I (2018) DEM Modeling and Experimental Analysis of the Static Behavior of a DryJoints Masonry Cross Vaults. Construction and Building Materials 170: 111-20. https://doi.org/10.1016/j.conbuildmat.2018.02.202.

Gaetani A, Monti G, Lourenço P B, Marcari G (2015) Masonry Cross Vaults: An Overview of the Historical Developments. AID Monuments 2015. Materials Techniques Restoration for Architectural Heritage Reusing, 589-601.

Gaetani A (2016) 'Design and Analysis of Cross Vaults Along History'. International Journal of Architectural Heritage 10 (7): 841-56. https://doi.org/10.1080/15583058.2015.1132020.

Heyman, J (1995). The Stone Skeleton: Structural Engineering of Masonry Architecture. University Press, Cambridge.

Huerta S (2004) Arcos, Bóvedas y Cúpulas. Geometría y Equilibrio En El Cálculo Tradicional de Estructuras de Fábrica. Instituto Juan de Herrera, Madrid.

Lagomarsino S, Cattari S (2015) PERPETUATE Guidelines for Seismic Performance-Based Assessment of Cultural Heritage Masonry Structures. Bulletin of Earthquake Engineering 13 (1): 13-47. https://doi.org/10.1007/s10518-014-9674-1.

Lagomarsino S, Resemini S (2009) The Assessment of Damage Limitation State in the Seismic Analysis of Monumental Buildings. Earthquake Spectra 25 (2): 323-46. https://doi.org/10.1193/1.3110242.

De Lorenzis L, Dejong M J, Ochsendorf J A (2007) Failure of Masonry Arches under Impulse Base Motion. Earthquake Engineering \& Structural Dynamics 36 (14): 2119-36. https://doi.org/10.1002/eqe.719.

Lourenço P B, Ramos L F (2004) Characterization of Cyclic Behavior of Dry Masonry Joints. Journal of Structural Engineering 130 (5): 779-86. https://doi.org/10.1061/(ASCE)0733-9445(2004)130:5(779).

Mark, R, Abel J F, O'Neill K (1973) Photoelastic and Finite-Element Analysis of a Quadripartite Vault. Experimental Mechanics 13 (8): 322-29.https://doi.org/10.1007/BF02322391.

De Matteis G, Cacace D, Rouhi J (2019) Masonry Vaults: Architectural Evolution, Structural Behaviour and Collapse Mechanisms. Paper presented at the $7^{\text {th }}$ Structural Engineers World Congress. Istanbul.

De Matteis G, Mazzolani F M (2012) The Fossanova Church: Seismic Vulnerability Assessment by Numeric and Physical Testing. International Journal of Architectural Heritage, no. December. https://doi.org/10.1080/15583050903078903.

Mendes N, Lourenço P B, Campos Costa A (2014) Shaking Table Testing of an Existing Masonry Building: Assessment and Improvement of the Seismic Performance, Earthquake Engineering \& Structural Dynamics 43 (August 2013): 247-66. https://doi.org/10.1002/eqe. 
Milani G, Rossi M, Calderini C, Lagomarsino S (2016) Tilting Plane Tests on a Small-Scale Masonry Cross Vault: Experimental Results and Numerical Simulations through a Heterogeneous Approach. Engineering Structures 123: 300-312. https://doi.org/10.1016/j.engstruct.2016.05.017.

Miltiadou-Fezans A (2008) A Multidisciplinary Approach for the Structural Restoration of the Katholikon of Dafni Monastery in Attica Greece. Paper presented at Structural Analysis of Historical Constructions Conference, London.

Ministero delle Infrastrutture e Trasporti. 2018. Capitolo 3 - NTC 2018 - Azioni sulle costruzioni, issued 2018 (in Italian).

Modena C (2020) Recent Advances of Italian Recommendations and Standards on Structural Safety of Existing Masonry Structures. In Brick and Block Masonry - From Historical to Sustainable Masonry, 42-57. https://doi.org/10.1201/9781003098508-5.

Moretti M, Azzara R M, Bono A (2013) Terremoto in Emilia Romagna: Quaderni. (in Italian).

National Civil Protection Service. 2013. Manuale per La Compilazione Della Scheda per II Rilievo Del Danno Ai Beni Culturali, Chiese - MODELLO A-DC. Ed. by Simona Papa and Giacomo Di Pasquale.

Oppenheim, Irving J (1992) The Masonry Arch as a Four-Link Mechanism under Base Motion. Earthquake Engineering \& Structural Dynamics 21 (11): 1005-17. https://doi.org/10.1002/eqe.4290211105.

Podestà S, Brignola A, Curti E, Parodi S, Lemme A (2010) Damage Assessment and Seismic Vulnerability of Churches: The Abruzzo Earthquake. Ingegneria Sismica XXVII (1): 21-35.

Pulatsu B, Erdogmus E, Martis Bretas E, Lourenço P B (2019) In-Plane Static Response of Dry-Joint Masonry Arch-Pier Structures. AEI 2019: Integrated Building Solutions - The National Agenda - Proceedings of the Architectural Engineering National Conference 2019, no. April: 240-48.

https://doi.org/10.1061/9780784482261.028.

Ramos L F (2007) Damage Identification on Masonry Structures Based on Vibration Signatures. Universidade do Minho.

Regione Toscana. 2003. Istruzioni Tecniche per l'interpretazione Ed II Rilievo per Macroelementi Del Danno e Della Vulnerabilità Sismica Delle Chiese. Venzone: ARX s.c.r.I.

Rossi M (2015) Evaluation of the Seismic Response of Masonry Cross Vaults. Dissertation, Università degli Studi di Genova.

Rossi M, Calderini C, Lagomarsino S (2016) Experimental Testing of the Seismic In-Plane Displacement Capacity of Masonry Cross Vaults through a Scale Model. Bulletin of Earthquake Engineering 14 (1): $261-$ 81. https://doi.org/10.1007/s10518-015-9815-1. 
Rossi M, Calderini C, Lagomarsino S, Milani G (2015) Seismic Response of Masonry Vaulted Structures: Experimental and Numerical Modelling'. Paper presented at the $9^{\text {th }}$ International Masonry Conference, Guimarães: Universidade do Minho.

Rossi M, Calderini C, Roselli I, et al. (2017) Seismic Analysis of a Masonry Cross Vault through Shaking Table Tests: The Case Study of the Dey Mosque in Algiers. Earthquake and Structures.

Rossi M, Calderini C, Roselli I, et al. (2020) Seismic Analysis of a Masonry Cross Vault through Shaking Table Tests: The Case Study of the Dey Mosque in Algiers. Earthquake and Structures 18 (1): 57-72. https://doi.org/10.12989/eas.2020.18.1.057.

Rossi M, Barentin C C, Van Mele T, Block P (2017a) Collapse Analysis of Unreinforced Masonry Vaults Using 3D-Printed Scale-Model Testing'. Paper presented at the $7^{\text {th }}$ International Conference on Advances in Experimental Structural Engineering Collapse.

Rossi M, Barentin C C, Van Mele T, Block P (2017b) Experimental Study on the Behaviour of Masonry Pavilion Vaults on Spreading Supports. Structures 11 (May): 110-20.

https://doi.org/10.1016/j.istruc.2017.04.008.

Shapiro E E (2012) Collapse Mechanisms of Small-Scale Unreinforced Masonry Vaults'. Dissertation, Massachusetts Institute of Technology. http://hdl.handle.net/1721.1/72648.

Sharma S, Tomassetti U, Grottoli L, Graziotti F (2020) Two-Way Bending Experimental Response of URM Walls Subjected to Combined Horizontal and Vertical Seismic Excitation. Engineering Structures 219 (July): 110537. https://doi.org/10.1016/j.engstruct.2020.110537.

Theodossopoulos D, Sinha B P, Usmani A S (2003) Case Study of the Failure of a Cross Vault: Church of Holyrood Abbey. Journal of Architectural Engineering 9 (3): 109-17. https://doi.org/10.1061/(ASCE)10760431(2003)9:3(109).

Theodossopoulos D, Sinha B P, Usmani A S, Macdonald A J (2002) Assessment of the Structural Response of Masonry Cross Vaults. Strain 38 (3): 119-27. https://doi.org/10.1046/j.0039-2103.2002.00021.x.

Tomaževič M (1999) Earthquake-Resistant Design of Masonry Buildings. Edited by Imperial College Press. Imperial College Press.

Torres B, Bertolesi E, Calderón P A et al. (2019) A Full-Scale Timbrel Cross Vault Subjected to Vertical Cyclical Displacements in One of Its Supports. Engineering Structures 183 (July 2018): 791-804. https://doi.org/10.1016/j.engstruct.2019.01.054.

Torres B, Bertolesi E, Moragues J J et al. (2019) Experimental Investigation of a Full-Scale Timbrel Masonry Cross Vault Subjected to Vertical Settlement. Construction and Building Materials 221: 421-32. https://doi.org/10.1016/j.conbuildmat.2019.06.015. 
Williams M S, Albuerne A, Lawson V, Yip F (2010) Model Scale Shaking Table Tests on Masonry Barrel and Cross Vaults. Paper presented at the $15^{\text {th }}$ WCEE Conference, Lisbon.

\section{Figures}

Mechanism

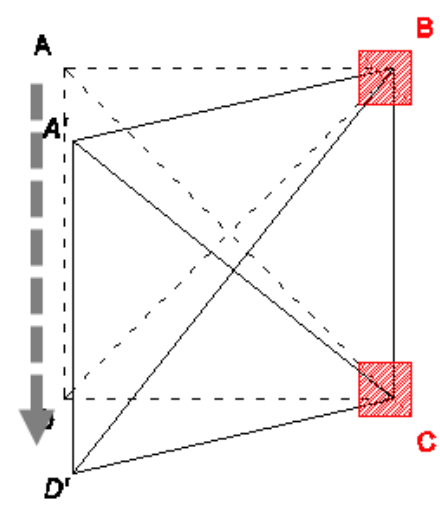

Church

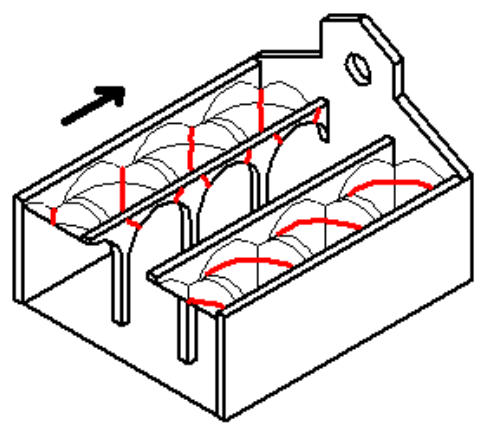

Palace

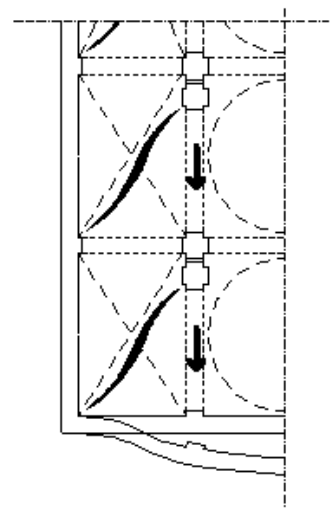

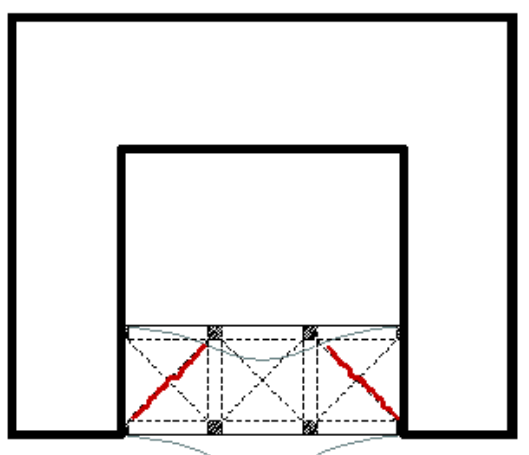

Figure 1

In-plane shear displacement settings considered in the experimental campaign (Rossi, Calderini, and Lagomarsino 2016)

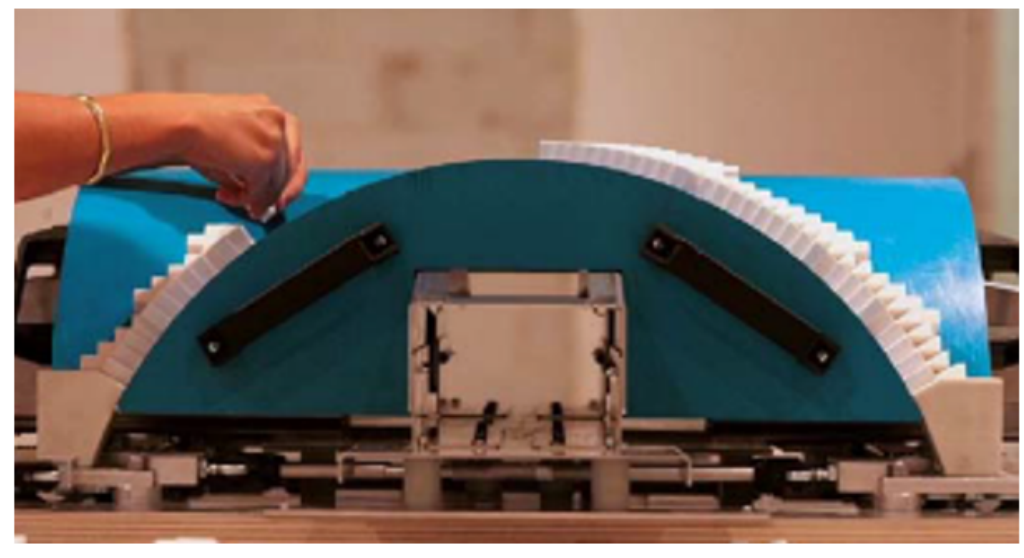

(a)

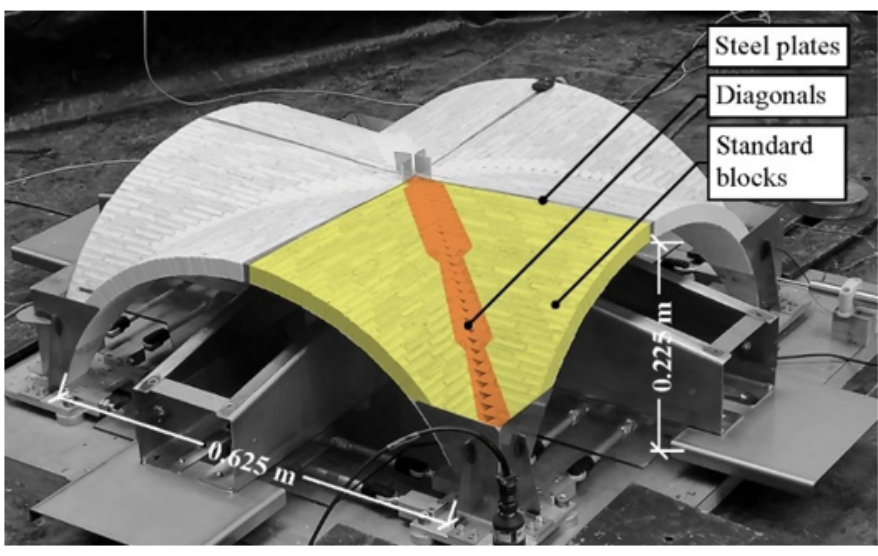

(b)

Figure 2

Reduced scale vault: (a) details of the construction on the plywood scaffolding and (b) at the end of the construction. Adapted from Rossi et al. $(2015 ; 2016)$. 

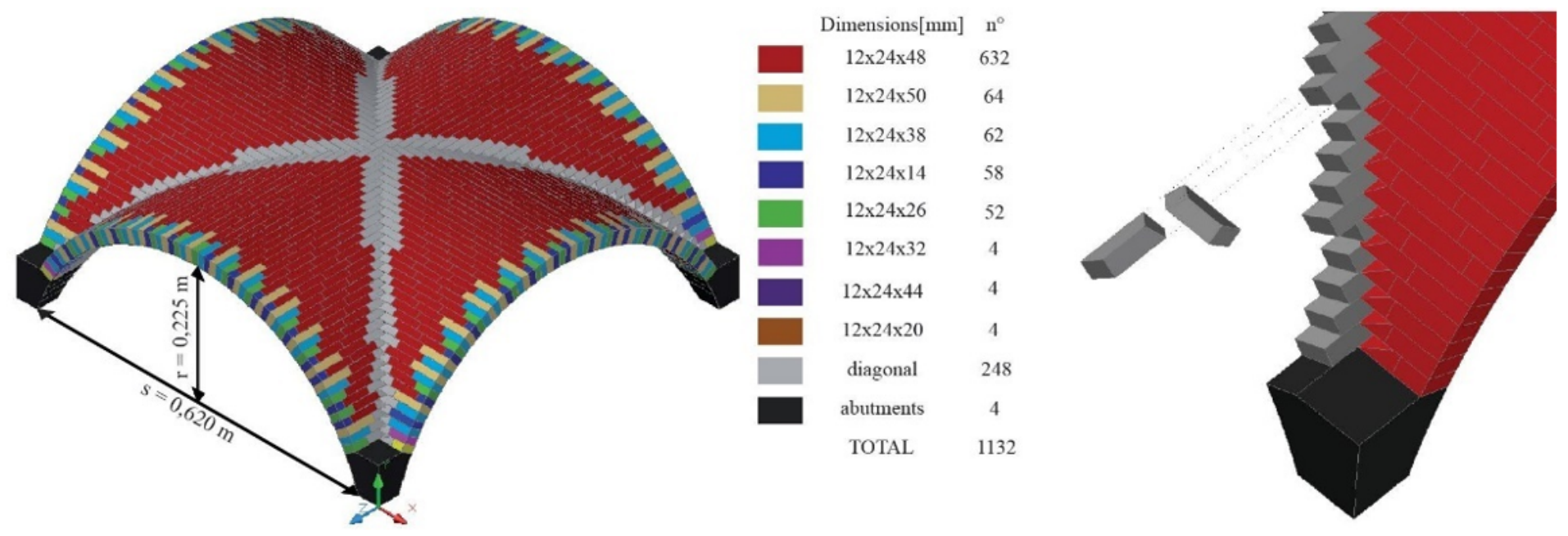

\section{Figure 3}

Geometry of the reduced-scale vault and blocks stereotomy of the diagonal blocks (Rossi, Calderini, and Lagomarsino 2016).
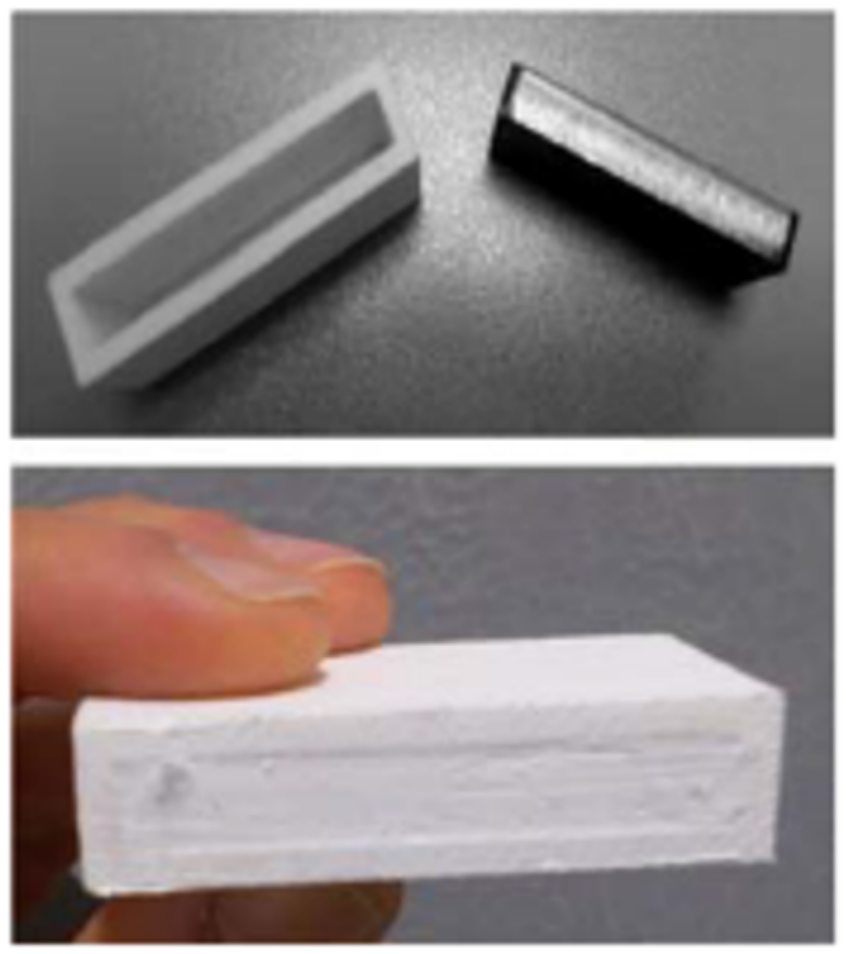

(a)

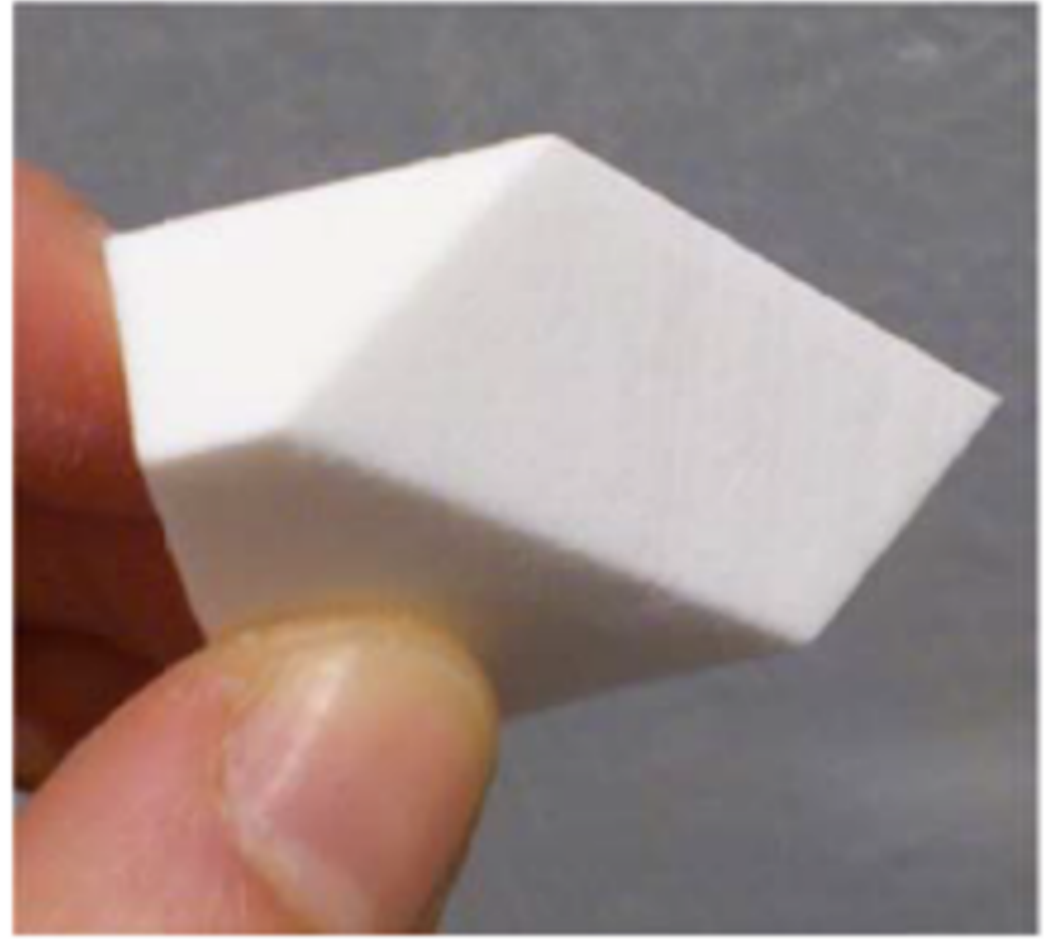

(b)

\section{Figure 4}

Details of the standard blocks with steel core (a) and the elements of the diagonals (b). 

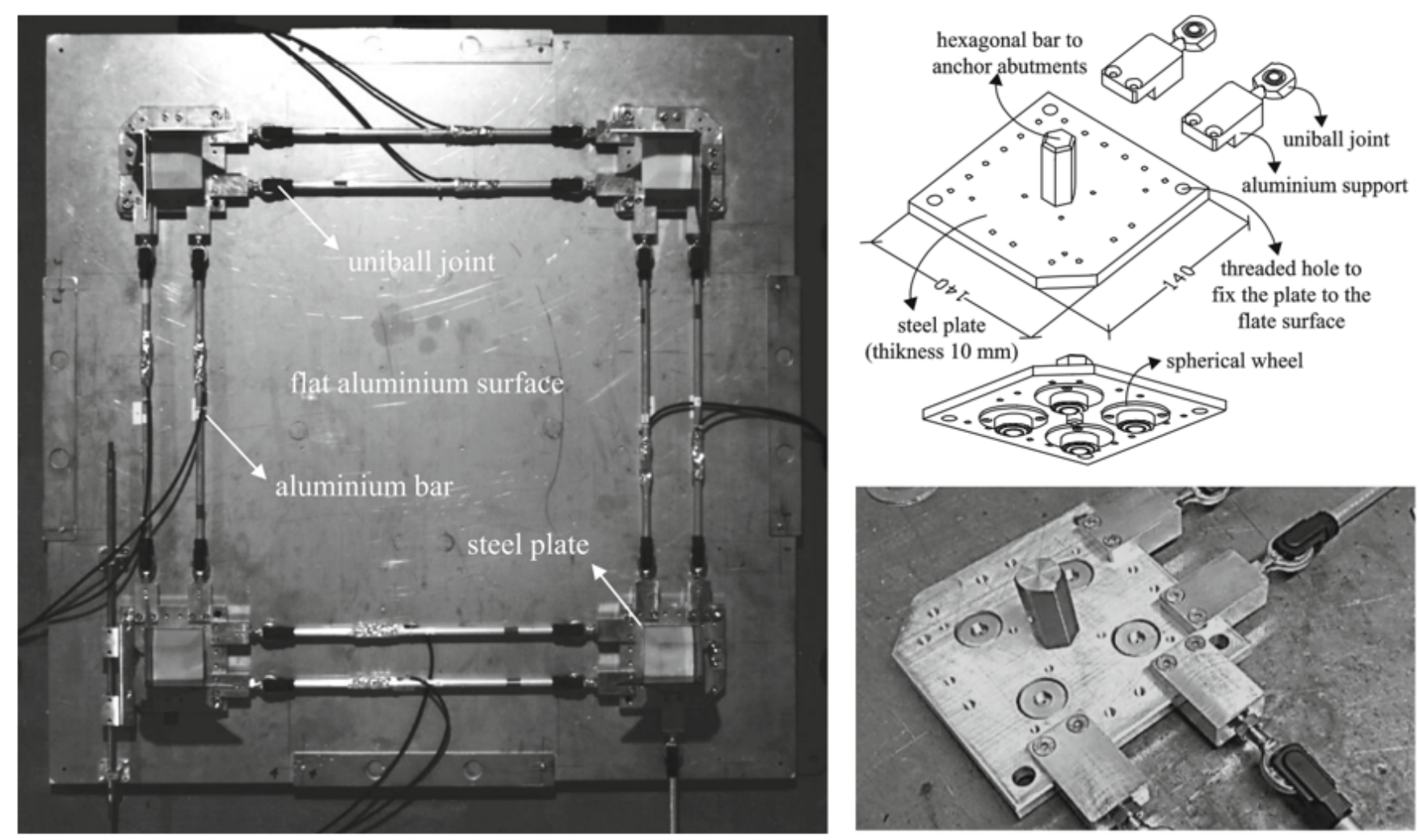

(thikness $10 \mathrm{~mm}$ ) $\rightarrow$ spherical wheel

(a)

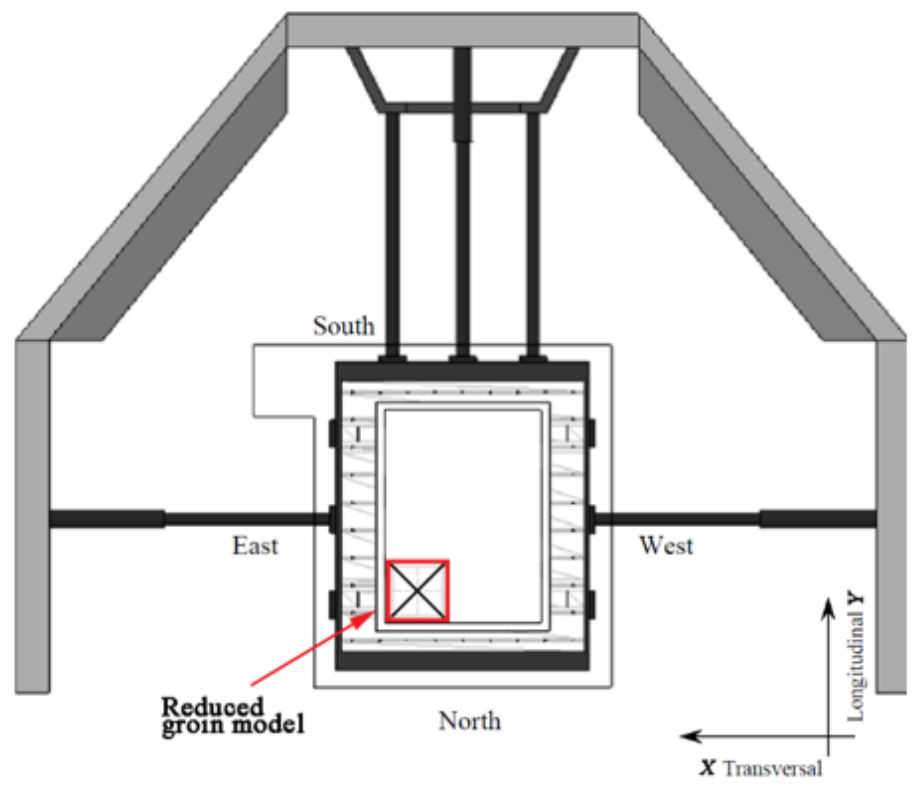

(b)

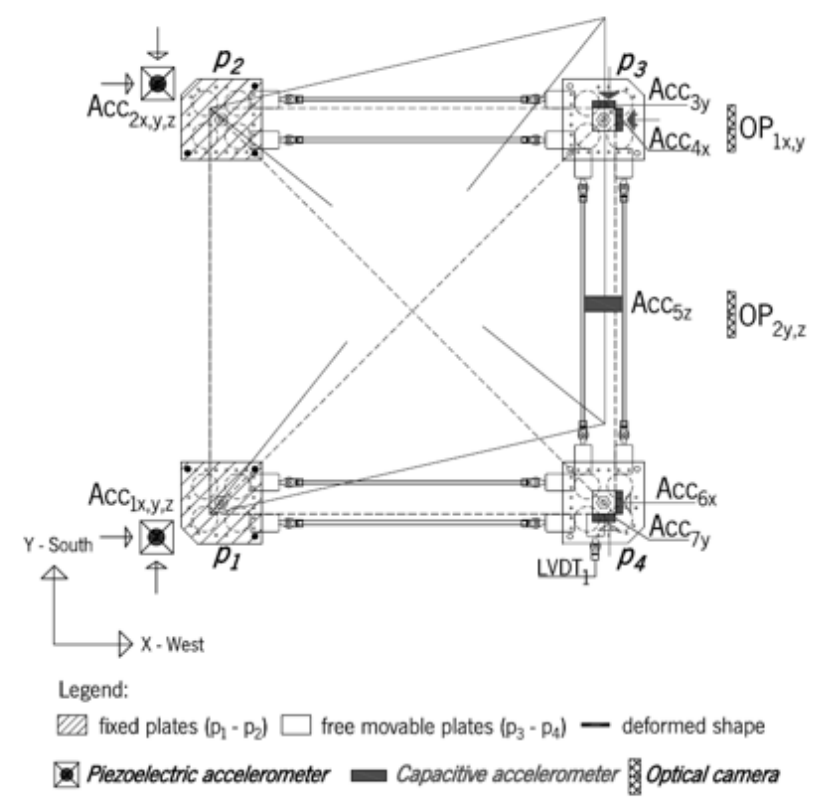

(c)

\section{Figure 5}

Experimental setup: (a) movable frame to apply displacements for the quasi-static tests carried out by Rossi et al. (2016); (b) plan with the location of the mock-up (highlighted in red) in the shaking table; (c) instrumentation adopted in the shake table tests (top view). 

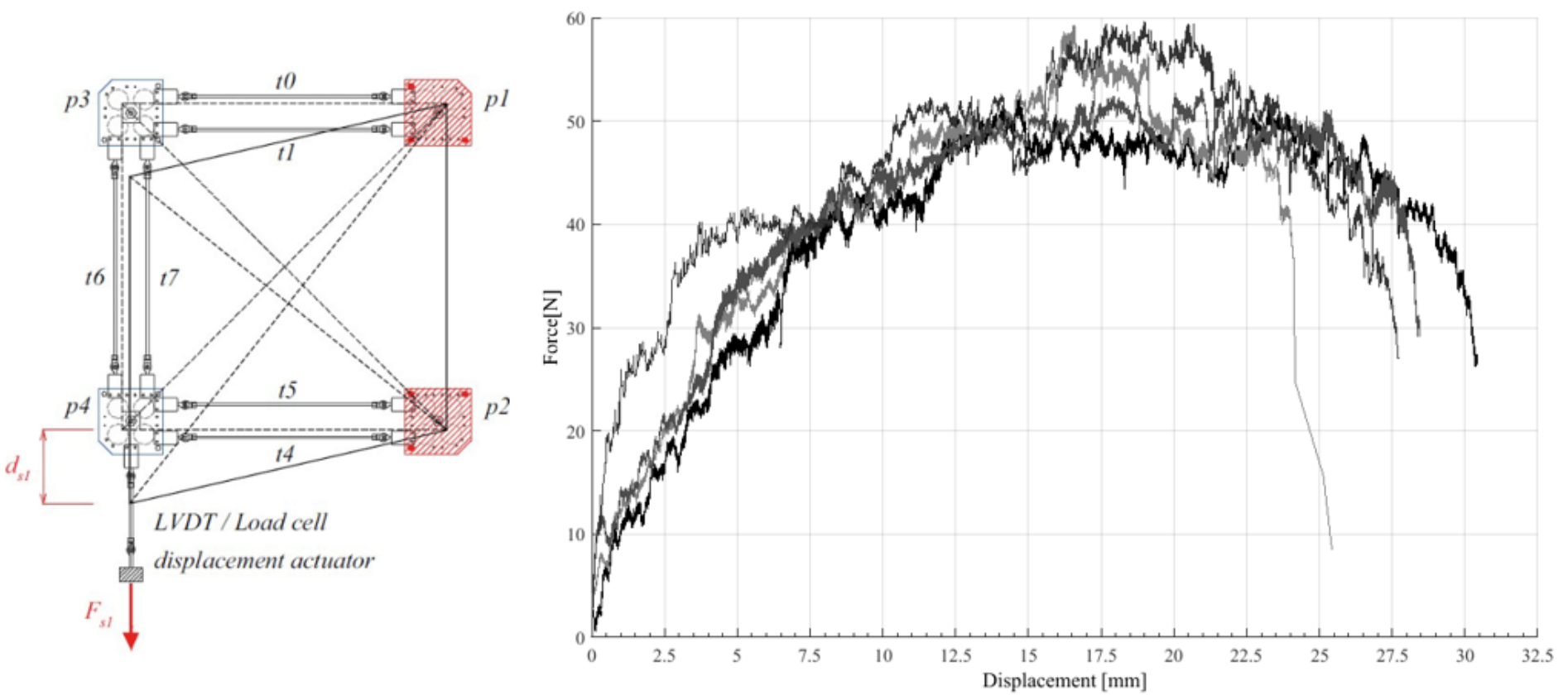

Legend: - $\quad$ deformed shape

t0-t7: chains fixed plates

p1-p4: steel plates

free movable plates

\section{Figure 6}

Test setup and results of the quasi-static tests (Rossi, Calderini, and Lagomarsino 2016)

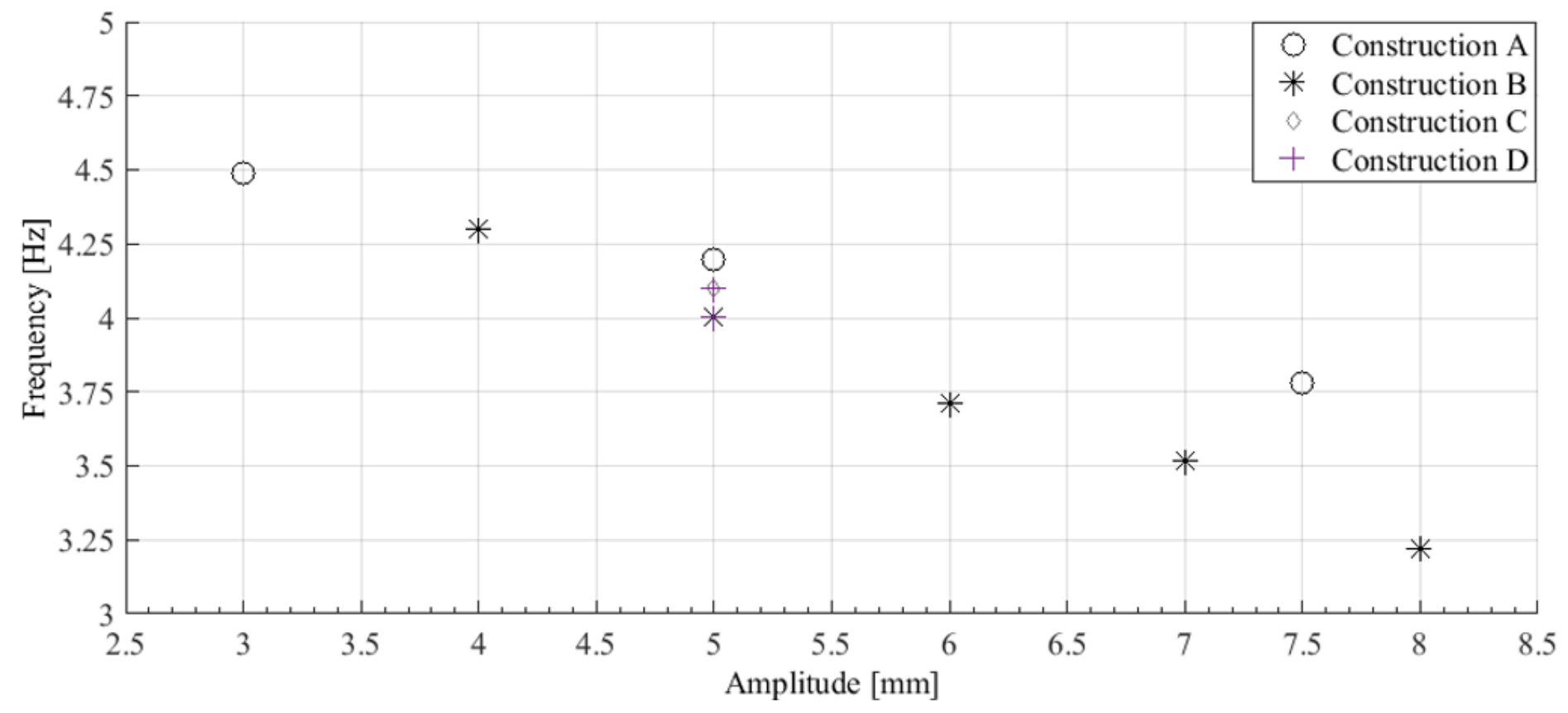

Figure 7

Frequencies as a function of the signal amplitude of the dynamic identification tests. 


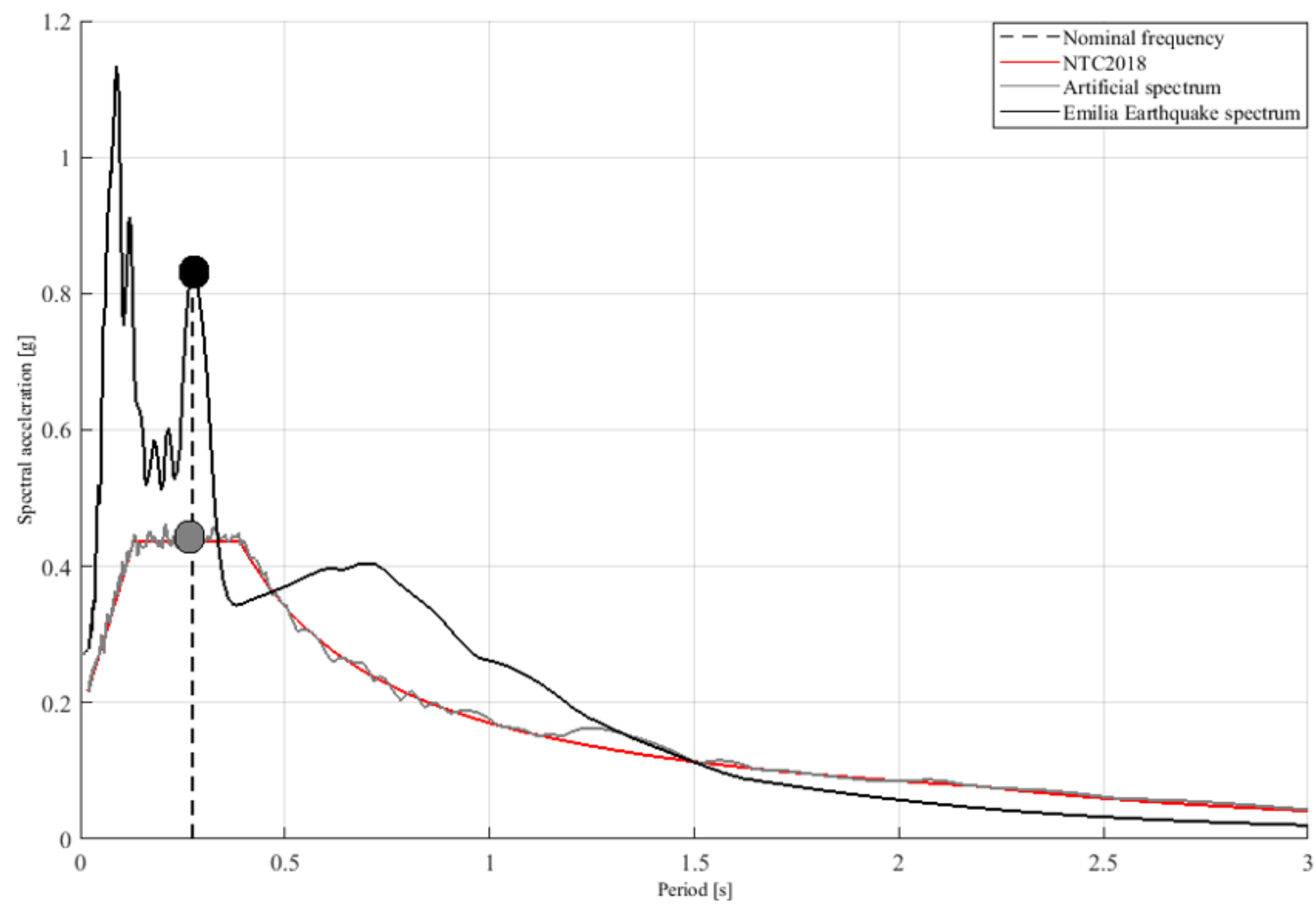

Figure 8

Elastic response spectra of the selected input signals (Emilia target input and artificial accelerogram) and comparison with the 475-years return period design spectrum for Mirandola according to NTC2018. The periods are scaled according to the similitude relationships. 
Acceleration time history

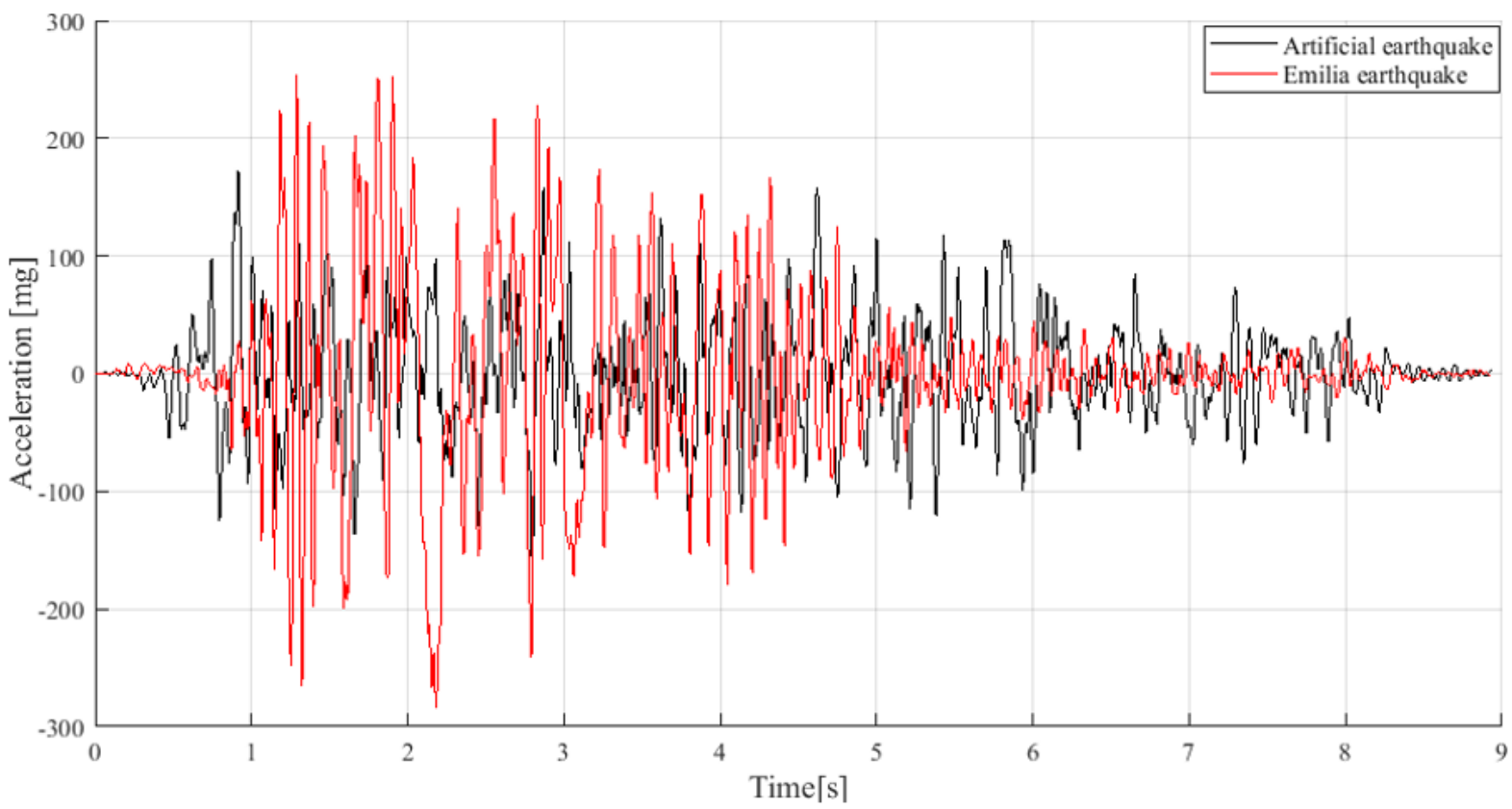

PGA [mg] Emilia EQ: 284.6 Artificial: 173.3 RMSA [mg] Emilia EQ: 72.50 Artificial: 46.75 Displacement time history

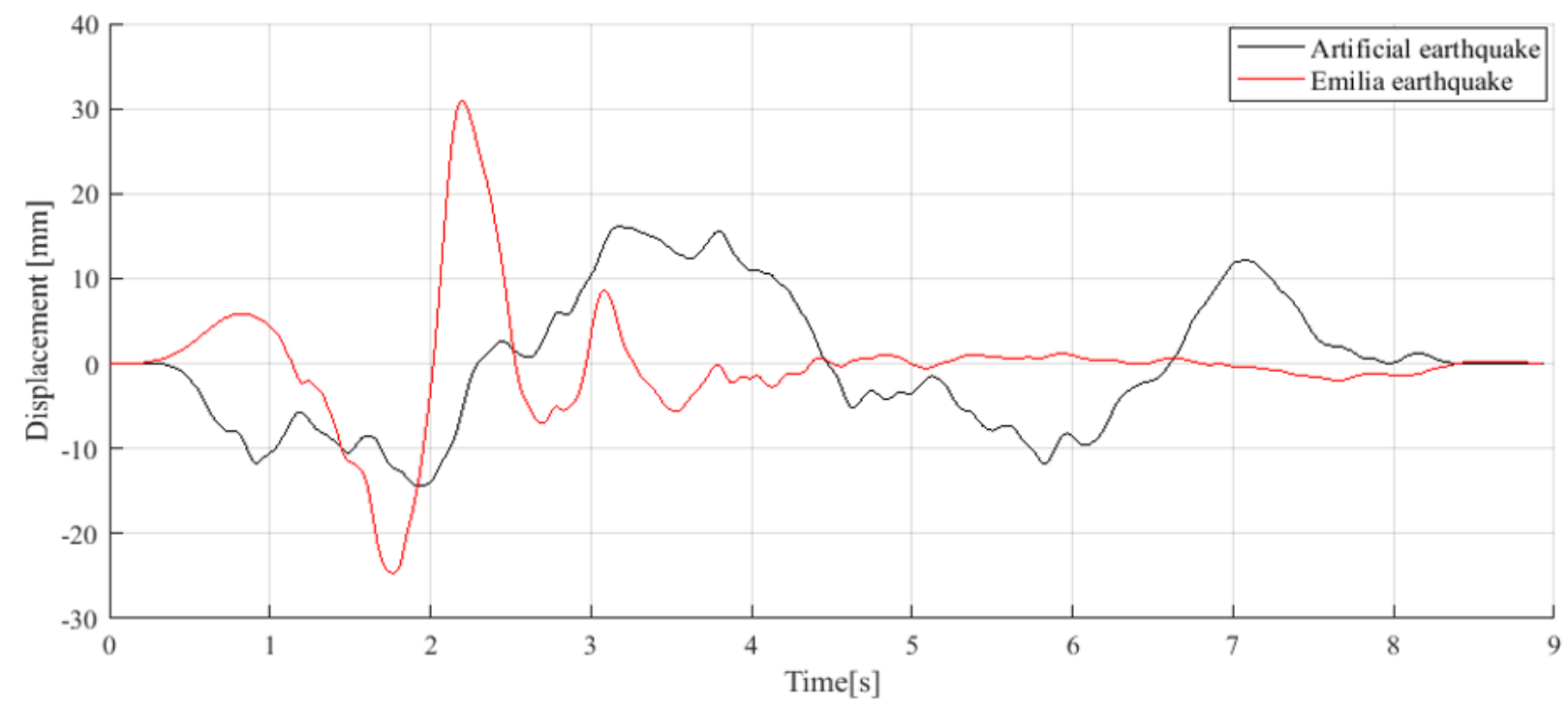

PGD [mm] Emilia EQ: 31.00 Artificial:16.10 RMSD [mm] Emilia EQ: 7.09 Artificial: 7.87

\section{Figure 9}

Scaled time histories of accelerations and displacements for the reduced mock-up. (Emilia and artificial inputs - amplitude equal to $100 \%$ ) 

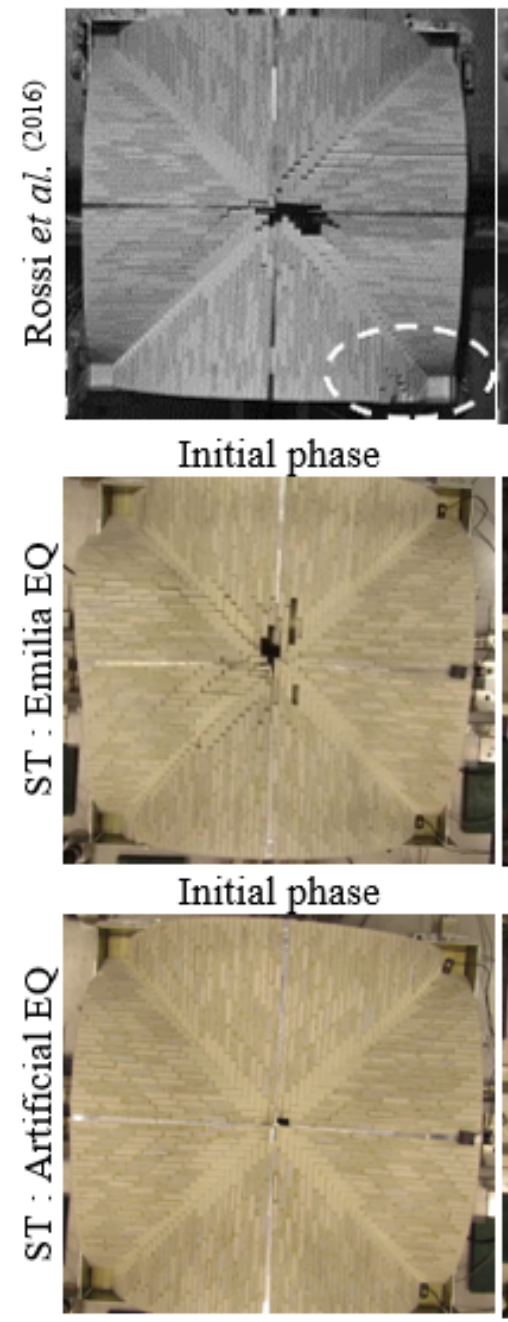

Initial phase

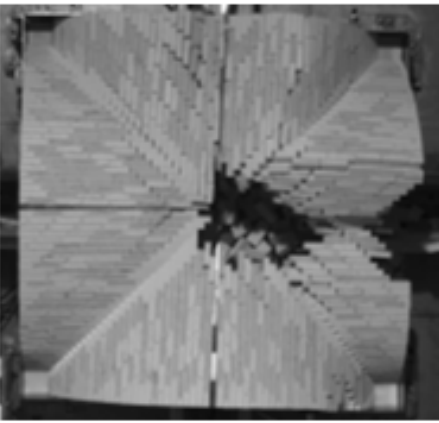

First hinges

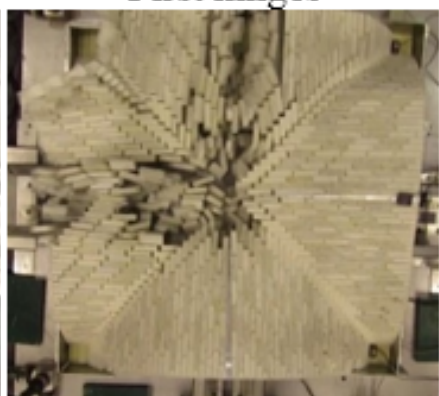

First hinges

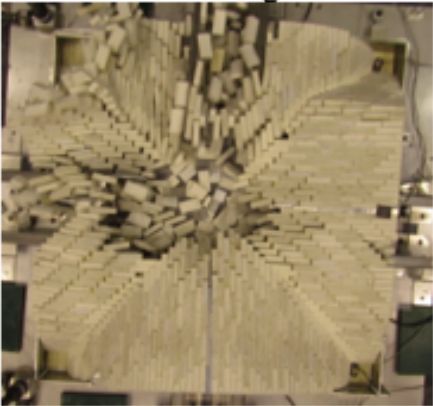

First hinges

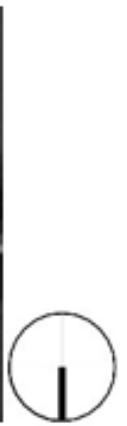

$\mathrm{N}$

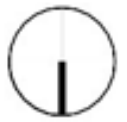

$\mathrm{N}$

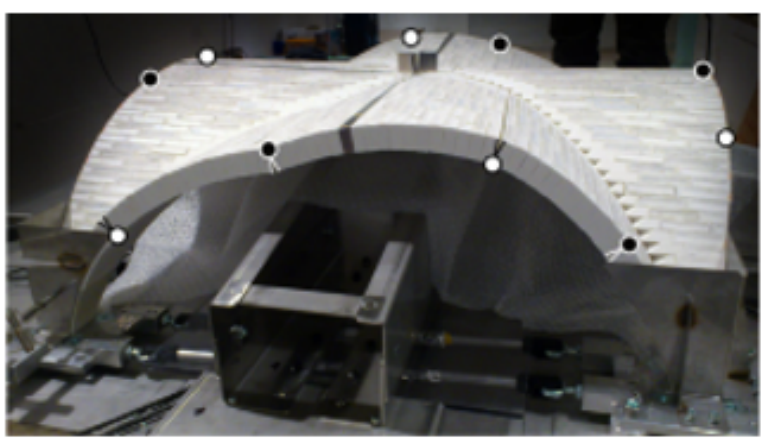

Lateral view (West side) at the end of the tests

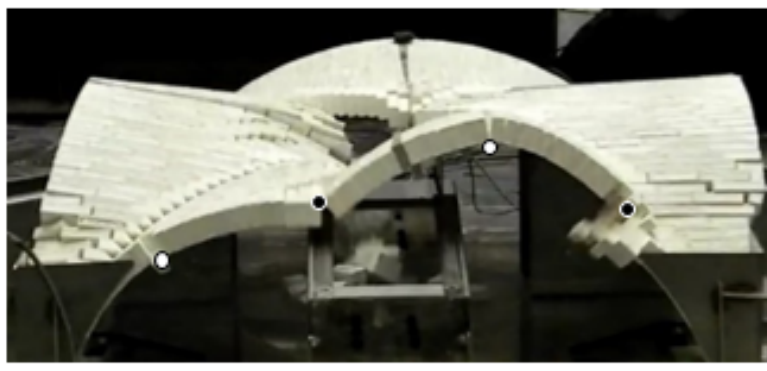

Lateral view (East side) at the end of the tests

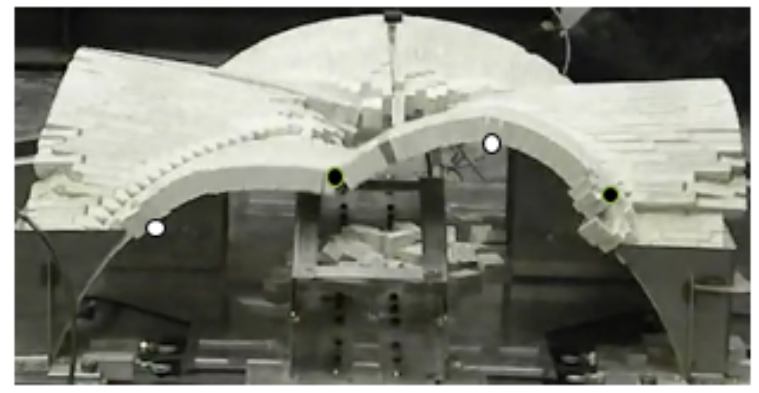

Lateral view (East side) at the end of the tests

\section{Figure 10}

In-plane shear mechanism: pictures of the test (white circles indicate the location of the hinges at the extrados, while black circles indicate the location of the hinges at the intrados). 

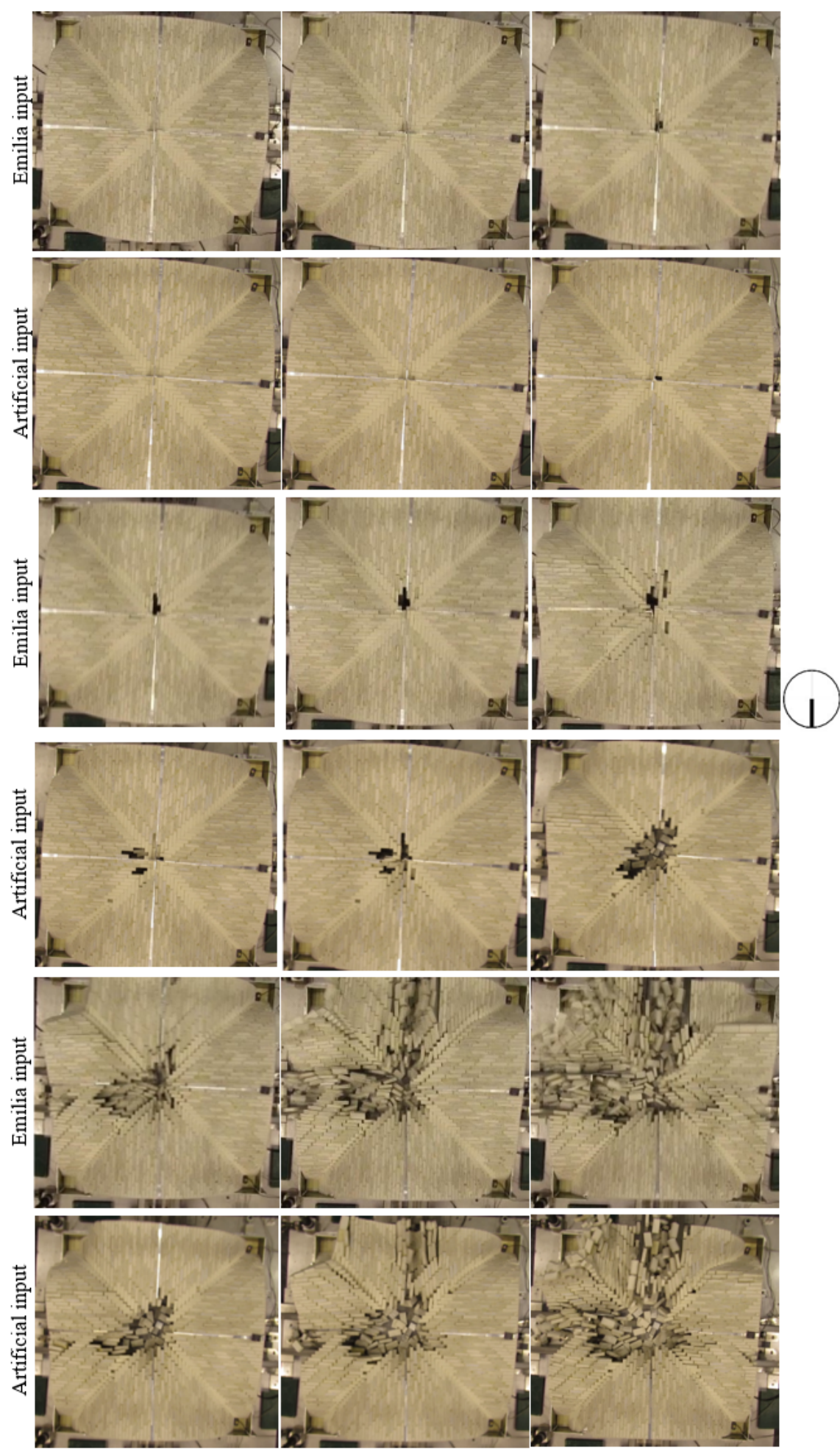

\section{Figure 11}

Damage progression of the mock-up during the intense phase of the Emilia seismic input $75 \%$ vs. the artificial input (200\%) (5 frames/s). (Left side: fixed supports p1 - p2; right side: movable supports p3 p4). 

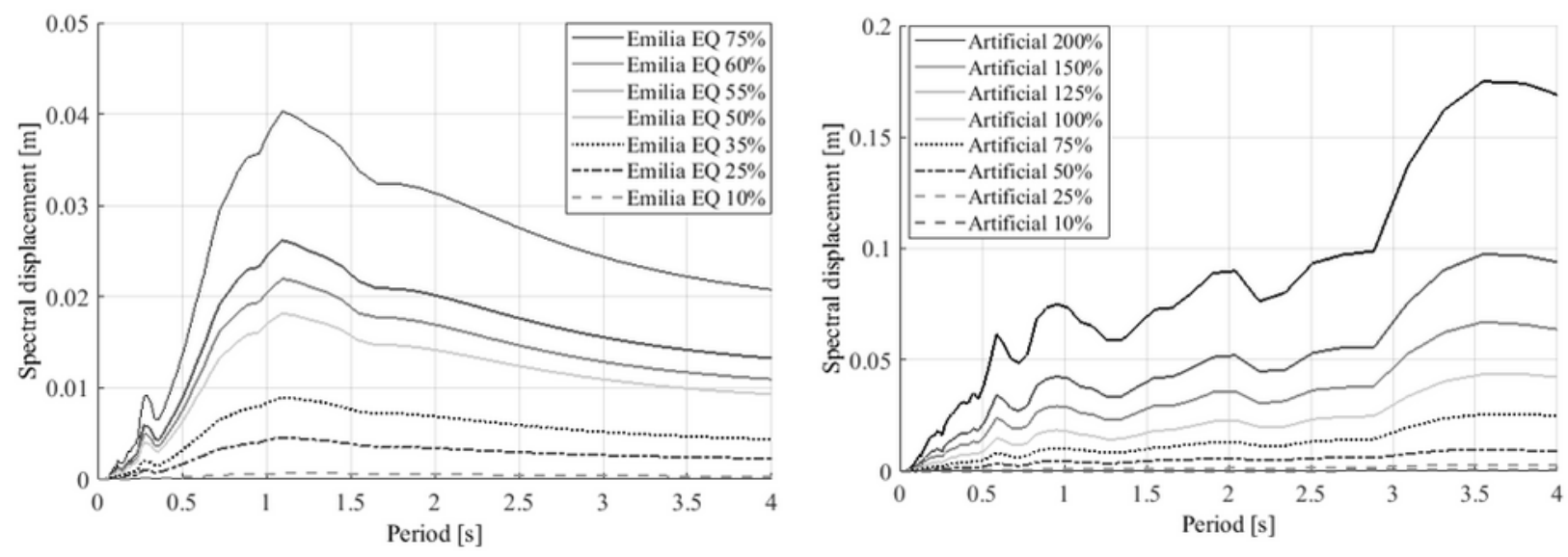

Displacement response spectra
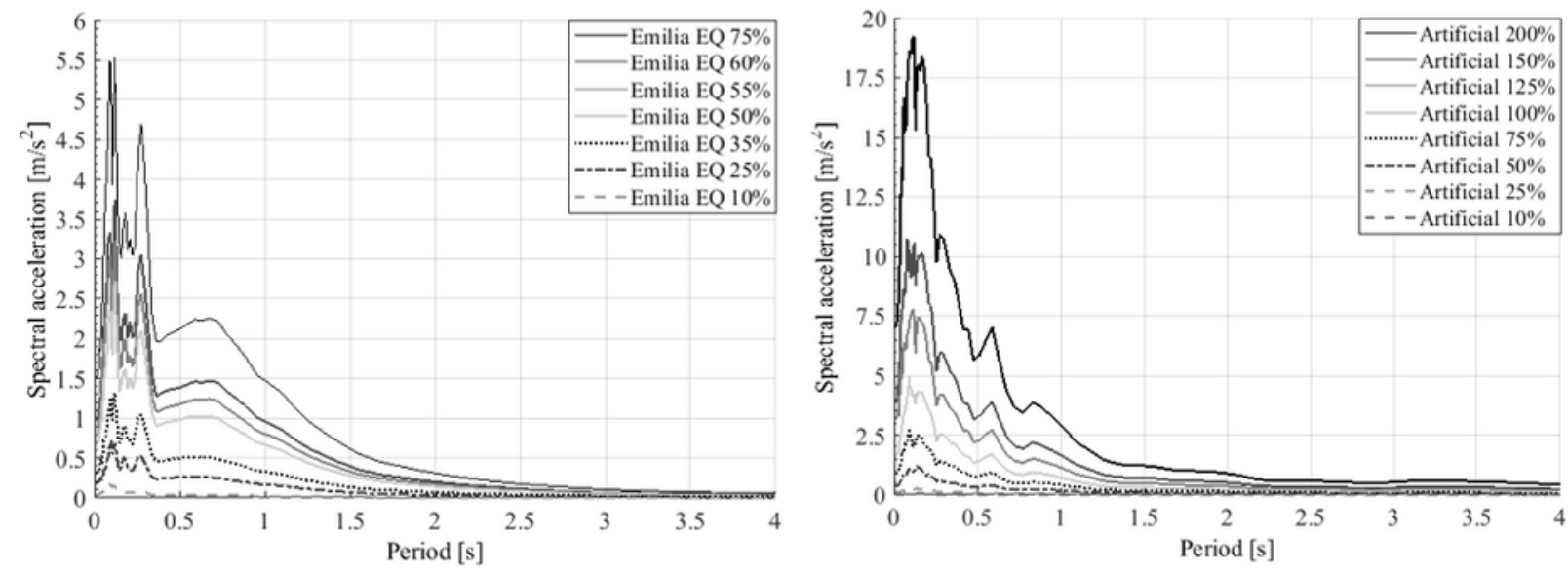

Acceleration response spectra
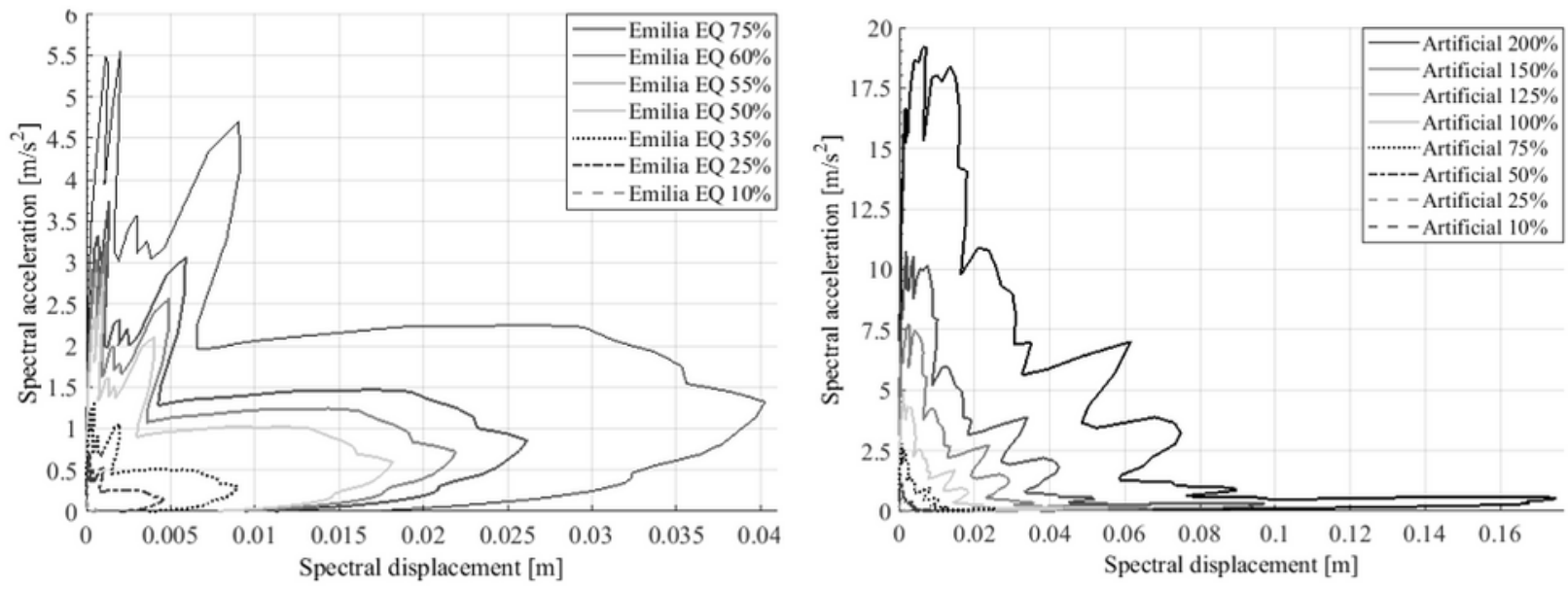

Corresponding ADRS

Figure 12

Displacement and acceleration response spectra for the signals measured at the shake table for the two inputs: Emilia input (left) and artificial input (right) 


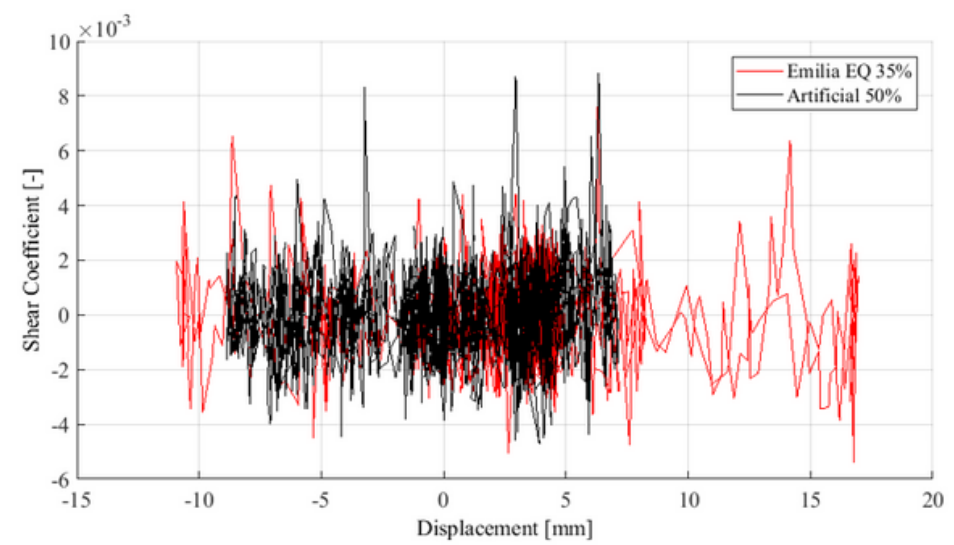

(a)

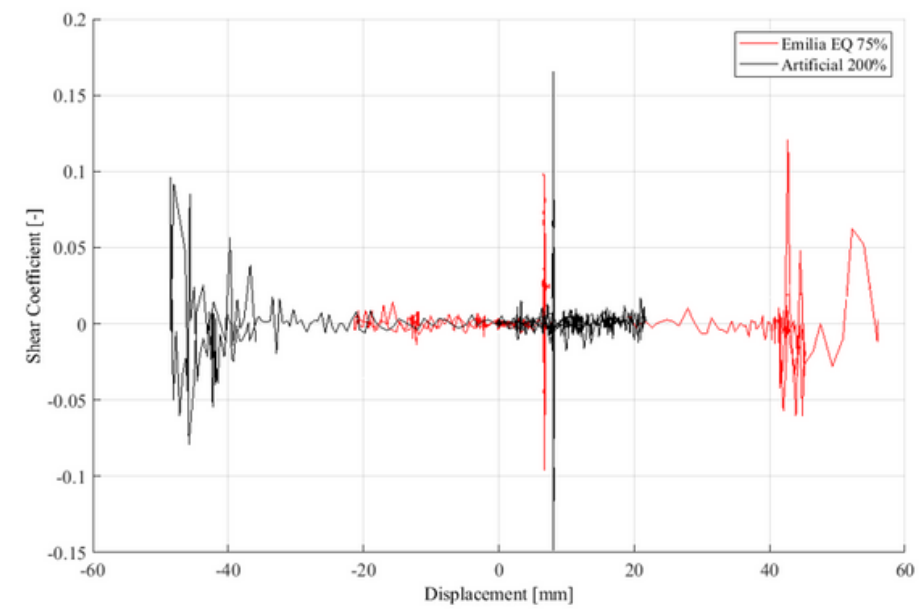

(b)

\section{Figure 13}

Hysteretic behaviour (base shear coefficient vs top arch displacement) for different stages of testing: Emilia EQ 35\% vs artificial EQ 50\% (a) and Emilia EQ 75\% vs artificial EQ 200\% (at the collapse) (b).

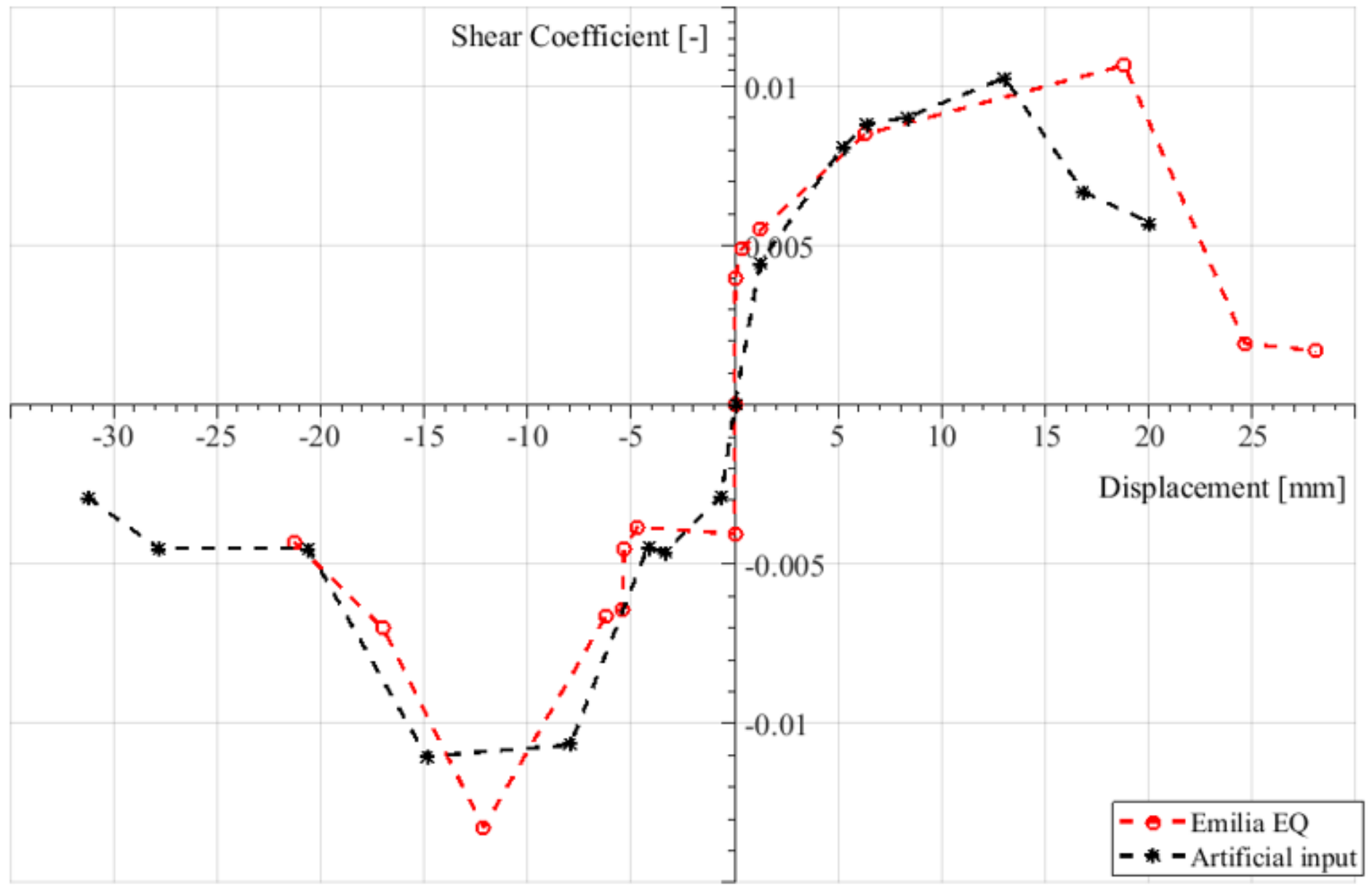

\section{Figure 14}


Experimental capacity curve, in terms of base shear coefficient and displacement at the key of the arch (OP2y).

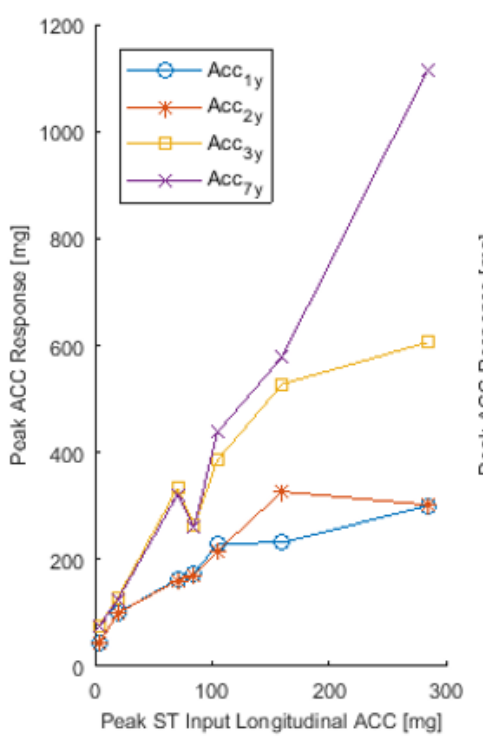

Emilia input

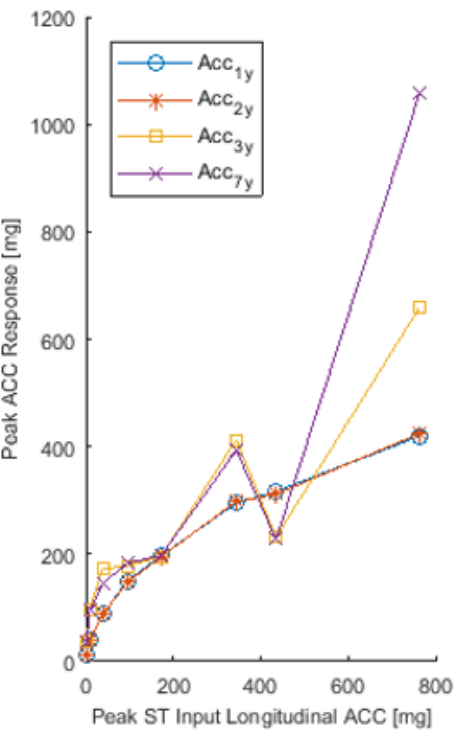

Artificial input

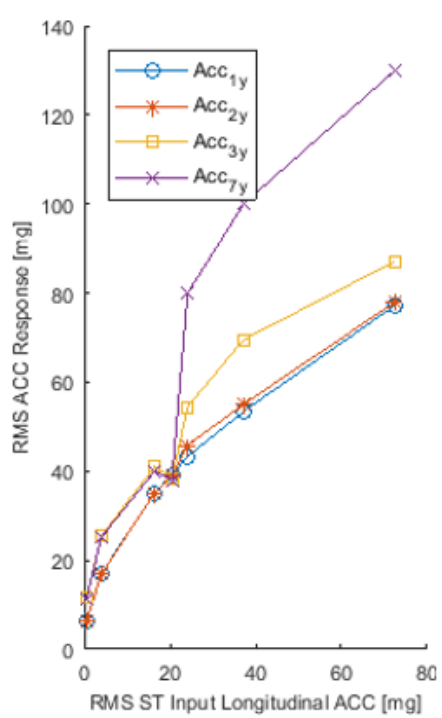

Emilia input

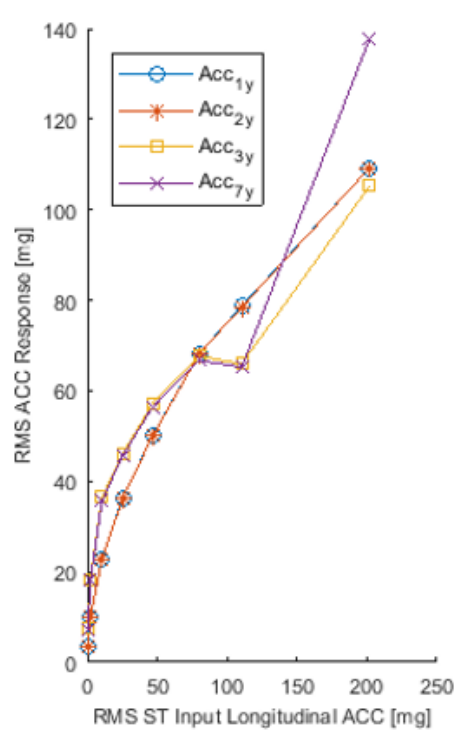

Artificial input

\section{Figure 15}

Peak and RMS acceleration of the response for the reduced-scale vault in the longitudinal direction. 